\title{
纳米材料形貌和性能调控的仿生自组装研究进展
}

\author{
李华金金，陈俊勇，肖洲，乐弦，余显波，向军辉 \\ (中国科学院大学 材料科学与光电技术学院, 材料科学与光电技术中心, 北京 101400)
}

摘 要: 纳米材料在纳米尺度展现出的特殊性质, 相较于宏观尺度材料表现出众多优异特性, 在力学、声学、光学、 磁学、电学、热学等各种领域具有良好的应用前景。纳米材料的仿生自组装技术模拟活体生命活动, 使纳米材料基 于非共价键的相互作用，自发形成稳定结构，现已成为制备纳米材料的主要方法之一。仿生自组装技术是“自上而 下”方法中的重要技术手段，这种合成方式有望代替传统的“自上而下”加工技术，实现单个原子或分子在纳米尺度 上构造特定结构和功能的器件。另外, 仿生自组装技术虽然以化学过程为主, 但又有物理过程, 并且结合了“仿生 学” 的优点, 具有定向构造纳米材料的特点, 是众多交叉学科的热门研究手段。本文重点介绍了纳米材料在形貌和 性能调控中不同的仿生自组装合成策略，包括屏蔽效应的位相选择自组装、双相界面协同效应的仿生自组装、场诱 导定位效应的功能器件一体化制备、光诱导自组装以及羟基氢键驱动的分相自组装, 总结了仿生自组装纳米材料的 特性，归纳了自组装技术在传感器、表面拉曼散射、生物医疗等领域的应用，并对纳米材料仿生自组装技术的发展 前景进行了展望。

关 键 词: 纳米材料; 仿生自组装; 屏蔽效应; 双相界面; 场诱导; 综述

中图分类号: TQ174 文献标志码: A

\section{Research Progress on Biomimetic Self-assembly of Nanomaterials in Morphology and Performance Control}

\author{
LI Huaxin, CHEN Junyong, XIAO Zhou, YUE Xian, YU Xianbo, XIANG Junhui
}

(Center of Materials Science and Opto-Electronics Engineering, College of Materials Sciences and Opto-Electronics Engineering, University of Chinese Academy of Sciences, Beijing 101400, China)

\begin{abstract}
Nano materials exhibit many excellent properties compared with macro scale materials due to their special properties at nanoscale. They exhibit good application prospects in various fields such as mechanics, acoustics, optics, magnetism, electricity, and thermology. In this fascinating field, biomimetic self-assembly technology of nano materials has become one of the main methods to prepare nano materials, which simulates the life activities in vivo and makes the nano materials spontaneously form stable structures based on the noncovalent bond interaction. The biomimetic self-assembly technology is an important technology in the "bottom-up" method, which is expected to replace the traditional "top-down" processing technology, and realize the construction of specific structure and function devices on the nanoscale by single atom or molecule. Moreover, although the bionic self-assembly technology is mainly involves chemical process, it also has
\end{abstract}

收稿日期: 2020-08-10；收到修改稿日期：2020-10-27；网络出版日期：2020-12-01

基金项目：国家“世界一流大学和一流学科”建设计划项目(111800XX62); 上海澍澎新材料科技有限公司、优澎(嘉兴)新材 料科技有限公司资助新型气凝胶材料制备技术项目(Y64101D1G2)

National "World-class Universities and First-class Disciplines" Construction Plan Project (111800XX62); Shanghai Shupeng New Material Technology Co., Ltd. and Youpeng (Jiaxing) New Material Technology Co., Ltd. Funded New Aerogel Material Preparation Technology Project (Y64101D1G2)

作者简介：李华崟金(1994-), 女，博士研究生. E-mail: lihuaxin17@mails.ucas.ac.cn LI Huaxin(1994-), female, PhD candidate. E-mail: lihuaxin17@mails.ucas.ac.cn

通信作者：向军辉，教授. E-mail: xiangjh@ucas.edu.cn XIANG Junhui, professor. E-mail: xingjh@ucas.edu.cn 
physical process, and combines advantages of "bionics" and has characteristics of directional construction of nano materials, which is a hot research means of many interdisciplines. This paper reviews different biomimetic self-assembly synthesis strategies for nano materials in morphology and performance control, including phase selective self-assembly of shielding effect, bionic self-assembly of biphase interface synergy effect, integrated fabrication of functional devices with field induced localization effect, photoinduced self-assembly and phase separation self-assembly driven by hydroxyl hydrogen bond. The characteristics of biomimetic self-assembled nano materials are summarized. This paper also introduced the application of self-assembly technology in sensors, surface Raman scattering, biomedicine and other fields. In addition, the prospects for the development of biomimetic self-assembly technology of nanomaterials are prospected.

Key words: nanomaterials; biomimetic self-assembly; shielding effect; biphasic interface; field induction; review

纳米材料是具有纳米尺度(尺寸介于 $0.1 \sim 100 \mathrm{~nm}$ 范围)结构单元的材料 ${ }^{[1]}$ 。利用其在原子、分子以及 纳米尺度上表现出来的特殊电学 ${ }^{[2-3]}$ 、磁学 ${ }^{[4]}$ 和光 学 ${ }^{[5-6]}$ 等性质, 可以制备出结构和功能一体化的纳 米器件, 实现对单个纳米颗粒的排布、纳米结构单 元构筑以及在纳米尺度上加工过程的有效调控, 是 实现纳米器件结构功能一体化的关键 ${ }^{[7]}$ 。目前常 用的纳米材料制备方法如气相沉积法 ${ }^{[8]}$ 、水热合成 法 ${ }^{[9-10]}$ 、层层自组装法 ${ }^{[11]}$ 、沉淀法 ${ }^{[12]}$ 、溶胶-凝胶 法 ${ }^{[13-16]}$ 等等, 尚不满足或不完全满足这一要求。

自然界中, DNA 分子的双螺旋结构 ${ }^{[17-18]}$ 、蛋白 质的聚集与折叠 ${ }^{[19]}$ 都展示出普遍存在的自组装现 象 ${ }^{[20-21]}$ 。自组装过程是若干结构单元之间同时自发 关联并结合在一起，形成一个有序整体的复杂协同 作用。随着仿生学和现代科学技术的快速发展, 仿 生自组装技术引起科学家的广泛关注, 在电子 ${ }^{[22]}$ 、信 息 ${ }^{[23]}$ 、材料 ${ }^{[24-25]}$ 和生命 ${ }^{[26-27]}$ 等众多领域占据越来越 重要的地位。通过仿生自组装技术, 借助分子间作用 力自发形成稳定并具有特定结构和功能的微纳米尺 度结构 ${ }^{[28]}$, 已经成为制备纳米材料和器件的重要手段 和方法之一。自组装技术是“自下而上(Bottom-up)”方 法中的重要技术手段, 这种合成方式可以代替传统的 “自上而下(Top-down)”加工技术, 实现单个原子或分 子在纳米尺度上构造特定结构和功能的器件 ${ }^{[29-30] 。}$

自然界中诸多结构单元在特定的环境下能够自 发进行组装, 形成各种各样的纳米结构, 通过探究 自然界自组装过程, 可以设计合成新型的仿生自组 装体系。本文概括了仿生自组装技术在纳米材料制 备领域的研究成果, 重点归纳了形貌和性能调控的 仿生自组装合成策略, 即基于屏蔽效应的位相选择 自组装、基于双相界面协同效应的仿生自组装、基 于场诱导定位效应的定向定位自组装, 以及羟基氢 键诱导等其他类型的仿生自组装。介绍了仿生自组 装技术在传感器、表面拉曼散射、生物医疗等领域 的应用, 并对仿生自组装技术在纳米材料领域的发 展前景进行了展望。

\section{1 形貌和性能调控的纳米材料仿生自 组装合成策略}

在自组装过程中, 基本结构单元在一定条件下 自发地排列组装成具有一定特征的次级结构。结构 单元间的相互作用是支撑自组装机制的重要因素 ${ }^{[31]}$ 。 根据不同的作用方式, 可以对自组装合成策略进行 分类, 例如借助内部作用力 (如屏蔽效应位相选择 自组装、双相协同效应自组装和羟基氢键驱动自组 装等)或基于外加作用场(如光场、电场和磁场)等等。 本文重点介绍以下几种代表类型。

\section{1 基于屏蔽效应的位相选择自组装}

在纳米尺度下, 不同类型的化学键可以作为调 节基本结构单元如团簇之间相互作用的工具。然而, 对团簇的大小和形状的精确控制、对环境因素的敏 感性以及对团簇内部亚结构之间的距离控制等, 是 自组装过程中的巨大挑战。利用仿生自组装合成策 略, 可以设计特定类型的化学键, 在特定的化学键 的驱动下达到自发组装特定组装体的目的。

一般来说, 采用层层自组装(layer-by-layer selfassembly)的方法进行二维材料的叠加, 可以实现叠 层垂直方向的有序调控, 但是难以实现二维平面内 的调控, 所得到的还不是完全意义上的自组装器 件。基于屏蔽效应的位相选择自组装, 是在二维平 面内定位控制纳米颗粒，构筑纳米功能器件。

对祄底选择性修饰不同的分子，通过分子间的 相互作用引导纳米颗粒组装, 是一种便捷有效的调 控手段。Xiang 等 ${ }^{[32]}$ 在 2004 年首次提出一种基于屏 蔽效应的位相选择自组装新策略(如图 1(a)), 即在 自组装过程中使用一种屏蔽试剂, 改变基底表面亲 疏水性, 可实现纳米材料在基底上选择性生长。在 该过程中, 首先需要对超疏水祄底表面特定位置进 行超亲水化处理，获得同时具有超亲水基团(极性 基团)和超疏水基团(非极性基团)的超疏水/超亲水 
(a)

Hydrophobic side Hydrophilic side

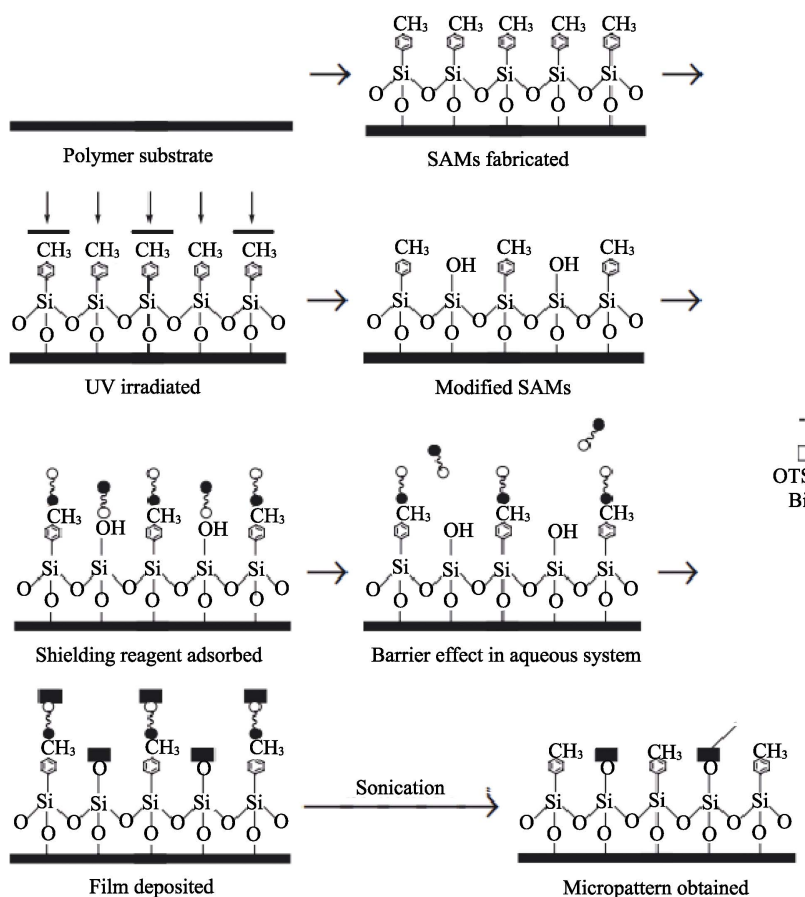

(b)
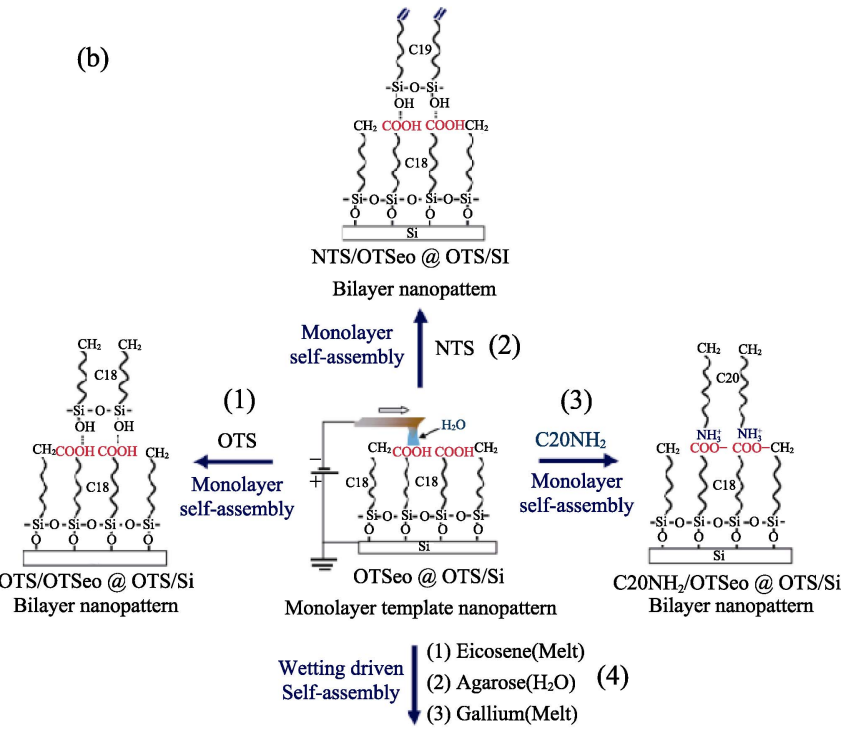

Eicosene, Agarose, Gallium/OTSeo @ OTS/Si

Nanopattern

图 1 (a)使用屏蔽试剂制作微图形的示意图 ${ }^{[32]}$, (b)基于屏蔽效应自组装表面纳米图案的路线图 ${ }^{[37]}$

Fig. 1 (a) Schematic procedure of micropattern fabrication employing a shielding reagent ${ }^{[32]}$ and (b) route of self-assembled surface nanopatterns based on shielding effect ${ }^{[37]}$

模板，然后将处理的祄底置于表面活性剂的水溶液 中，该超疏水/超亲水祄底表面将分别与疏水/亲水 基团作用，疏水端与超疏水基团作用使疏水表面被 表面活性剂覆盖，形成了屏蔽效应; 同时, 祄底模 板上暴露出大量的亲水基团，亲水性功能分子与祄 底表面亲水基团组装。Xiang 等 ${ }^{[32]}$ 通过该方法在柔 性祄底上制备自组装单分子薄膜(SAMs)，对特定位 点亲/疏水改性后, $\mathrm{TiO}_{2}$ 纳米颗粒可以在祄底上选择 生长。他们以聚对苯二甲酸乙二醇( PET)作为祄底, 通过在祄底上沉积一层甲苯三氯硅烷(TTCS) 得到 自组装单分子薄膜(SAMs), 然后利用紫外光照进行 紫外辐射亲/疏水改性, 得到 $-\mathrm{CH}_{3}$ 和 $-\mathrm{OH}$ 相间的分 子表面。将该模板浸泡在屏蔽试剂(十二烷苯磺酸钠) 的水溶液中，屏蔽试剂为线性分子结构，一端为亲 水基团, 另一端为疏水基团。沉积的 $\mathrm{TiO}_{2}$ 分子根据 相似相溶原理选择性针定在模板上, 线性结构使分 子在模板上形成了屏蔽效应。

上述研究结果表明，高表面能域更适合组装高 表面张力的功能材料, 而低表面张力的有机液体 (如醇、四氢呋喃、甲苯和二甲基甲酰胺等)或聚合 物溶液组装难度较大 ${ }^{[33-35]}$, 这主要归因于有机溶剂 和聚合物溶液表面张力较低 $\left(\gamma_{\mathrm{LV}}=15 \sim 30 \mathrm{mN} / \mathrm{m}\right)$, 更倾向于在低表面能域与非极性基团形成“屏蔽线 性分子”。在自组装过程中, 祄底表面既有低表面能
的“屏蔽”区域，又有高表面能的极性基团区域，两 者之间不对称的分子间作用力促使功能材料实现位 相选择组装。研究发现，针对不同的材料体系，不同 官能团的屏蔽剂对位相选择的影响显著不同 ${ }^{[36]}$ 。

Sagiv 等 ${ }^{[37]}$ 利用 SAMs 两亲分子的憎液性和屏 蔽效应，在 SAMs 模板上原位沉积制备出单官能团 $n$-烷基硅烷的三维(3D)模板图案, 如图 1(b)所示。研 究表明，由于 SAMs 表面基团不同的亲疏水特性， 在形成双功能有机硅烷的单层体系中，疏水基团和 亲水基团交替作用能够精确控制目标分子的定向组 装，从而构造出具有预期构型的单分子膜。

\section{2 基于双相界面协同效应的仿生自组装}

有机一无机双液相界面是生物体中生命活动的 重要反应位点, 几乎所有的活体反应都不同程度地 受到此类界面的影响。在仿生自组装过程中, 借此 类界面可以对材料生长的形貌起到调控作用。研究 表明, 以有机一无机双液相界面及自组装分子层作 为模板，可以实现纳米材料的分级结构自组装。由 该方法制备的材料可以获得复杂的表面形貌和分级 结构, 如梭状亚单元、微球结构和刺猬状结构等等。

纳米材料的双相界面自组装具有简便、环保、 易于控制和操作等诸多优点, 具备大规模生产的潜 力, 可用于合成功能性原料, 如半导体(碳纳米点, $\mathrm{PbS}, \mathrm{Zn}) 、$ 贵金属 $(\mathrm{Au}, \mathrm{Ag}, \mathrm{Pt})$ 、稀土苂光 $\left(\mathrm{TiO}_{2}, \mathrm{CuO}\right.$, 
$\left.\mathrm{ZrO}_{2}, \mathrm{SnO}_{2}, \mathrm{ZnO}\right)$ 和磁性纳米晶体 $\left(\mathrm{CoFe}_{2} \mathrm{O}_{4}\right)$ 等等。在 纳米功能器件制备方面也具有良好的发展前景, 例 如依靠低表面张力和亥姆霍兹自由能使纳米颗粒组 装成纳米薄膜等二维纳米结构, 在电子、催化、光 学和传感器等领域有广泛的应用。Brochard 等 ${ }^{[38]}$ 和 Binks ${ }^{[39]}$ 的研究发现, 微米级的固体粒子能在双液 相界面形成一层稳定的薄膜, 即 Pickering 乳液, Pickering 乳液的稳定机理如图 2 所示。粒子的尺寸 大小、粒子间相互作用以及双相界面之间的相互作 用决定了固体粒子在双相界面的吸附能力。固体颗 粒能否形成有效的稳定乳液, 还取决于三相接触角 $\theta$ 。对于亲水性颗粒(如金属氧化物), 颗粒浸入水相 的部分比浸入油相多, 即接触角 $\theta<90^{\circ}$ (图 2(a)), 此 时易形成油/水 $(\mathrm{O} / \mathrm{W})$ 乳液; 对于疏水性颗粒(如疏水 硅), 其接触角 $\theta>90^{\circ}$ (图 2(b)), 此时易形成水/油 (W/O) 乳液。根据 Pieranski 理论, 双液相界面自组 装被定义为一个可以自发构造多级有序结构的过程, 热力学因素和其他约束力都会影响界面自组装过 程。热力学中的自由能(系统减少的内能)可以转化 为对外做功, 是衡量在一个特定的热力学过程中系 统可对外输出的“有效能量”。Pieranski 的研究表明 水/油体系总自由能降低是粒子界面自组装的主要 驱动力 ${ }^{[40]}$ 。对于半径为 $r$ 的粒子, 界面总表面能变 化为:

$$
\Delta E=-\frac{\pi r^{2}}{\gamma_{\mathrm{O} / \mathrm{W}}}\left[\gamma_{\mathrm{O} / \mathrm{W}}-\left(\gamma_{\mathrm{P} / \mathrm{W}}-\gamma_{\mathrm{P} / \mathrm{O}}\right)\right]^{2}
$$

其中, $\gamma_{\mathrm{O} / \mathrm{W}} 、 \gamma_{\mathrm{P} / \mathrm{W}}$ 和 $\gamma_{\mathrm{P} / \mathrm{O}}$ 分别为油/水、粒子/水和粒子/ 油的表面张力系数。粒子在界面上的稳定性取决于 (a)
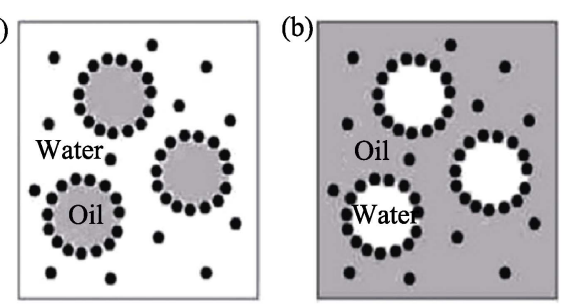

(c)

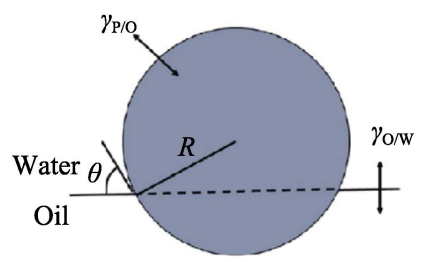

图 2 Pickering 乳液稳定机理示意图 ${ }^{[40]}$

Fig. 2 Schematic diagram of Pickering emulsion stability mechanism $^{[40]}$

(a) $\mathrm{O} / \mathrm{W}$ emulsion; (b) W/O emulsion; (c) Changes of surface tension when particles with radius rare adsorbed on the oil-water interface

有效半径。对于微米级的粒子, 界面总自由能减少 量远高于其热运动能量 $\left(k_{\mathrm{B}} T\right)$, 所以这些粒子无法自 发吸附到界面上; 而对于纳米粒子, $\Delta E$ 的数量级与 $k_{\mathrm{B}} T$ 相当, 能够在体相和界面之间形成动态吸附平衡。

生物材料具有多组分的特征，通常是由有序的 有机一无机杂化结构组成, 基于双相界面表面张力, 利用仿生自组装开发和制备不同形貌和功能的纳米 材料也是目前研究的热点之一。Tiwari 等 ${ }^{[41}$ 基于 Pieranski 理论，在水-二甲苯双相界面实现了自支撑 超薄聚亚胺分子分离膜的大面积制备, 如图 3 所示。 他们首先以 $1,3,5$-三(4-甲酰基苯基)苯(TFPB)和乙二 胺 $(E D A)$ 为单体, 在二甲苯溶剂中制备亚胺齐聚物 (a)

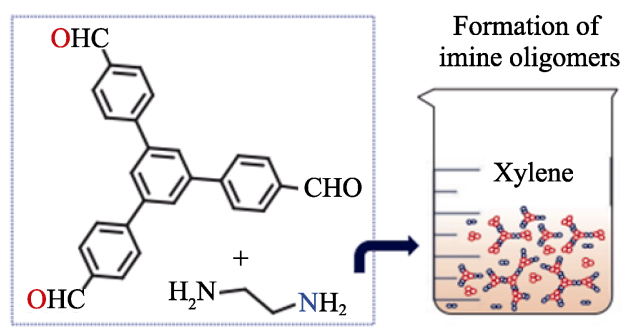

(b)

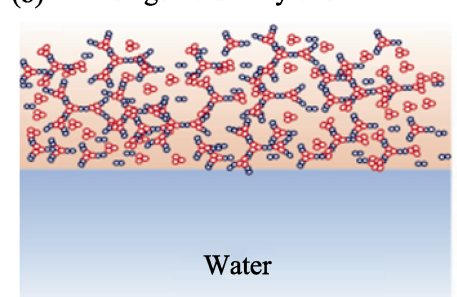

(c) Self-assembly of oligomers

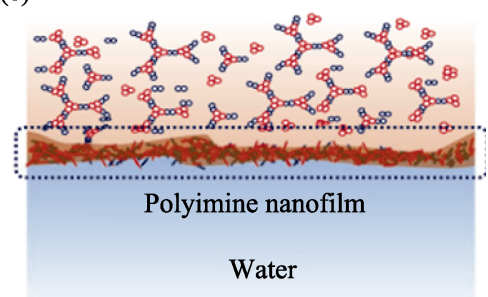

(d)
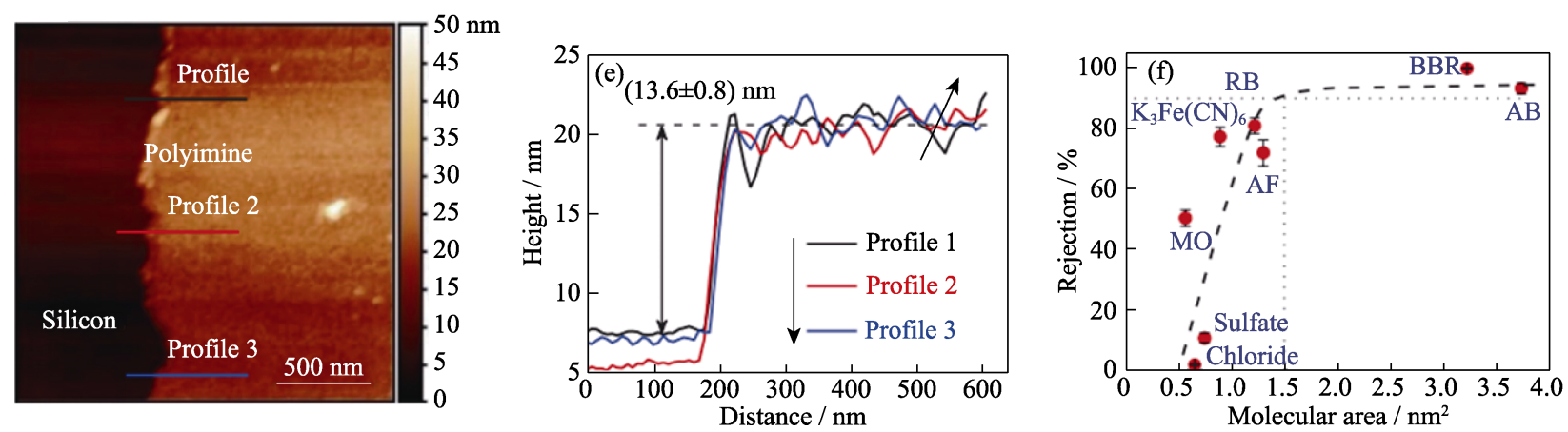

图 3 超薄聚亚胺膜制备过程及膜性能表征 ${ }^{[41]}$

Fig. 3 Preparation process and characterization of ultra-thin polyimide nanofilms ${ }^{[41]}$ (BBR: Brilliant Blue R; AB: Aniline Blue; AF: Acid Fuchsin; RB: Rose Bengal; MO: Methyl Orange) 
(a)

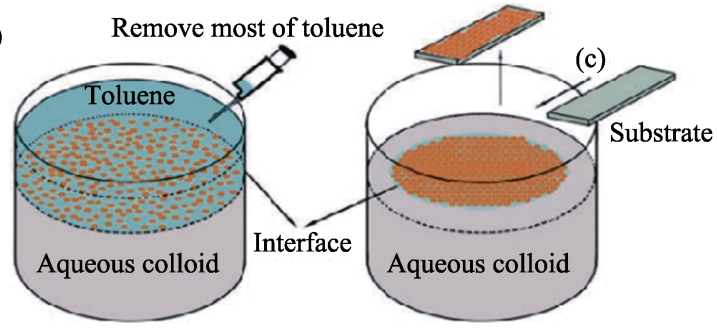

(c)

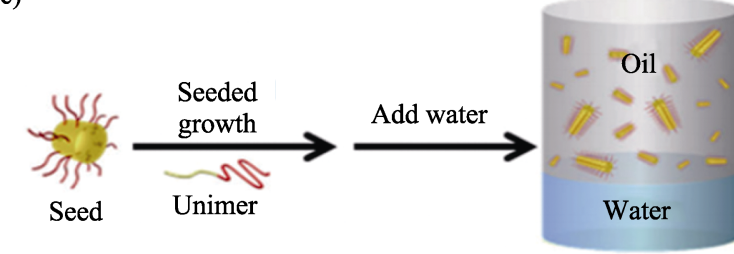

BCP 1

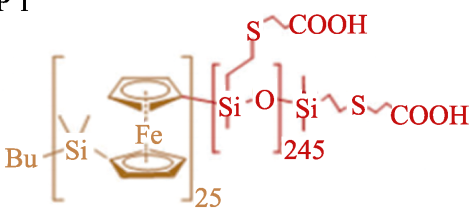

BCP 2-4

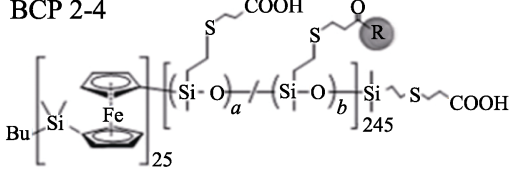

$\mathrm{BCP} 3$

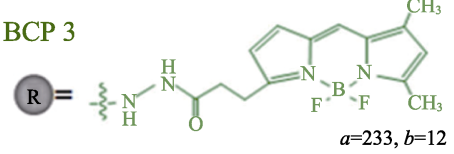

(b)
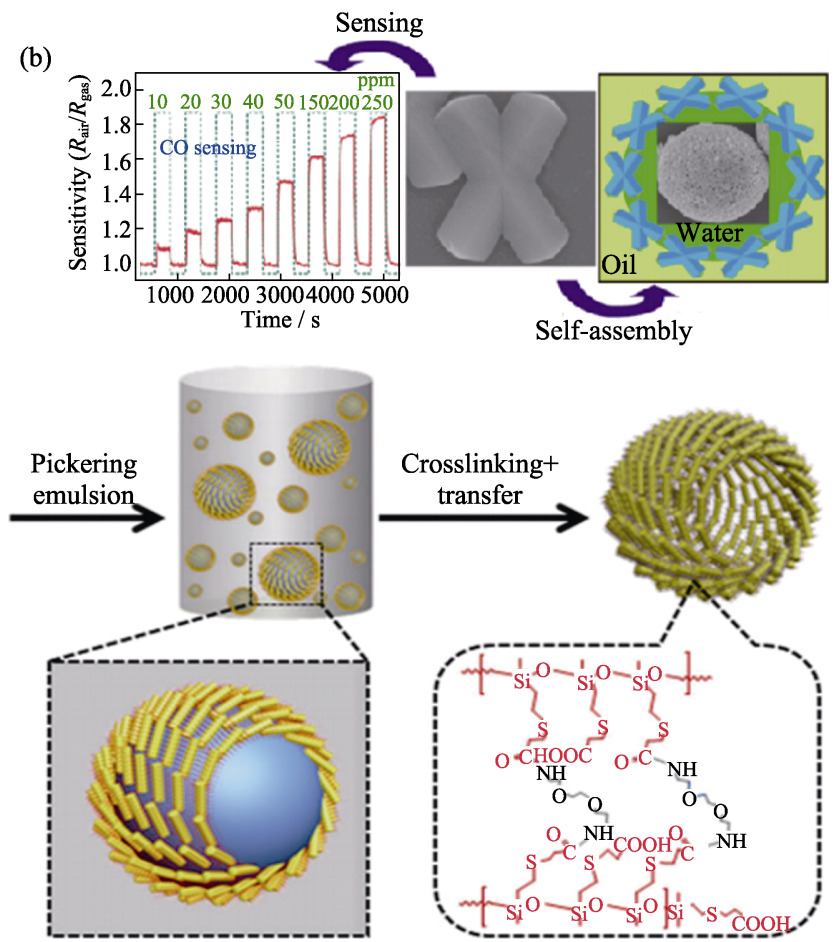

$\mathrm{BCP} 2$

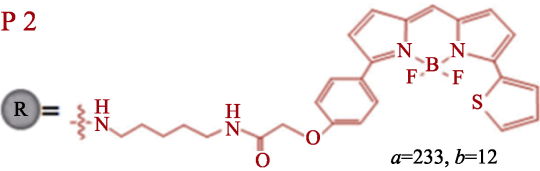

$\mathrm{BCP} 4$

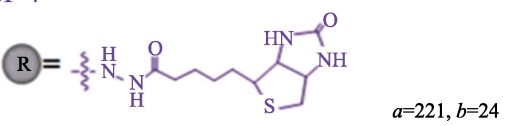

图 4 (a)界面自组装 MLFs 的形成和转移示意图 ${ }^{[42]}$, (b) 各向异性的 X 形针铁矿晶体在油/水界面处

自组装形成微米级空心球示意图 ${ }^{[44]}$, (c) 可结晶二嵌段共聚物在油/水双相界面自组装示意图 ${ }^{[45]}$

Fig. 4 (a) Schematic diagram of formation and transfer of interfacial self-assembly MLFs ${ }^{[42]}$; (b) Schematic diagram of anisotropic X-shaped goethite crystal self-assembly at oil/water interface to form micron scale hollow spheres ${ }^{[44]}$;

(c) Schematic diagram of self-assembly of crystalline diblock copolymer at oil/water interface ${ }^{[45]}$

(BCP: Block Copolymer)

悬浮溶液后倒入水溶液中, 构筑水-二甲苯双相界 面，基于水催化的界面缩聚和齐聚物自组装形成具 有交联网络结构的纳米级超薄聚亚胺膜。双相界面 缩聚反应 $3 \mathrm{~h}$ 后得到聚亚胺薄膜, 用 AFM 测得其厚 度约为 $14 \mathrm{~nm}$ 。研究表明在二氯甲烷-水和三氯甲烷水体系界面亦可自组装制备超薄聚亚胺膜。Sun 等 ${ }^{[42]}$ 报道了一种通用的油/水界面自组装的方法，在甲苯/ 水界面处, 亲水性的纳米粒子可自组装为有序单层 膜(MLFs，图 4(a)), 通过控制两相的界面张力，一 些典型的纳米颗粒(包括 $\mathrm{Au}, \mathrm{Pt}$ 和 $\mathrm{SiO}_{2}$ ) 体系可在两 相协同作用下自组装成有序 MLFs。Xiang 等 ${ }^{[43]}$ 在柔 性祄底上基于双相界面协同效应制备了刺猬状的多 碳酸钙微球。在该研究中, 以端基为-OH 的柔性聚 对苯二甲酸乙二酯(PET)单分子自组装膜(SAMs)为 祄底, 分别选用有机溶剂正己烷与 $\mathrm{Ca}(\mathrm{OH})_{2}$ 的饱和 水溶液为两相界面制备多级有序的多孔碳酸钙微
球。研究表明, 所构建的 SAMs 表面亲水基团和有 机相界面之间的协同作用是控制多孔碳酸钙微球多 级结构的重要因素。该研究为两相界面协同诱导纳 米颗粒自组装制备形貌各异的纳米材料提供了新的 思路。

随着纳米粒子(如 $\mathrm{CdSe}, \mathrm{Au}$ 等)功能化技术的发 展, 由纳米粒子组装制备新型功能材料成为研究的 热点。Song 等 ${ }^{[44]}$ 借助水热合成法制备出 $\mathrm{X}$ 形针铁 矿 $(\alpha-\mathrm{FeOOH})$ 晶体, 各向异性的 $\mathrm{X}$ 形针铁矿晶体在 油/水界面处可自组装形成微米级空心球, 通过相拓 扑变换获得具有相同形态的赤铁矿 $\left(\alpha-\mathrm{Fe}_{2} \mathrm{O}_{3}\right)$ 晶体 (图 4(b)), 主要归因于 $\mathrm{X}$ 形针铁矿晶体在油/水两相 协同作用下堆积，降低了系统的总自由能，X 形针 铁矿晶体组装在每个胶束的油水界面处形成了空心 球结构。 $\mathrm{X}$ 形赤铁矿晶体对 $\mathrm{CO}$ 和 $\mathrm{H}_{2}$ 气体表现出优 异的传感性能。 
利用 Pickering 乳化构筑具有仿生膜结构的组 装微囊也是仿生材料自组装领域的研究热点之一。 Dou 等 ${ }^{\left[{ }^{[5]}\right.}$ 制备了一系列具有润湿性和化学反应性的 可结晶二嵌段共聚物, 并在油/水双相界面自组装成 特定尺寸的核壳纳米结构(图 4(c)), 该方法可构建 一系列具有分层膜结构、表面化学性质稳定以及光 学性质稳定的胶束体。另外, 核壳纳米结构可以在 自组装后通过膜结构单元的原位外延伸长在结构上 进行修饰, 形成致密的网络状微胶囊。该研究结果 向胶体的界面组装迈出了一步, 胶体既保留了其组 成构件的固有生长活性, 同时又允许生物功能化, 在仿生胶囊、药物递送、催化和生物传感等领域具 有潜在的应用。

纳米粒子在界面上的稳定性取决于有效半径, 纳米粒子的尺寸与双相界面的自组装过程相关。Lee 等 ${ }^{[46]}$ 研究了 $\mathrm{Au}$ 纳米粒子 (AuNP)尺寸与自组装两相 界面之间的协同关系, 根据表面活性剂数量 $\left(N_{\mathrm{s}}\right)$ 评 估有机-无机杂化自组装结构中 AuNP 形成的有效 表面积 $\left(A_{\mathrm{s}}\right)$ 。研究结果表明, 在正常油/水相中, 由于 有效表面积 $\left(A_{\mathrm{s}}\right)$ 和回转半径 $\left(R_{\mathrm{g}}\right)$ 的减小, AuNP 的尺 寸随着表面活性剂数量 $\left(N_{\mathrm{s}}\right)$ 的增加而变小; 同时, 由 于亲水区有效膨胀, AuNP 的尺寸在反相(油包水)阶段 再次变大, 如图 5 所示。该研究结果有助于对纳米 粒子杂化体系的基本认识, 对生物医学应用以及有 机一无机杂化功能材料的发展具有参考价值。

\section{3 基于场诱导定位效应的功能器件一体化 制备}

仿生自组装过程中按照一定规则有序排列的纳 米组装体可以实现特定的结构和功能。但在部分自 组装过程中, 纳米颗粒是随机排布的, 且分布不均, 难以实现纳米组装体的结构功能一体化。为了按照 有序排列的方式获得纳米组装体仿生结构, 必须借 助“外力作用”对自组装过程进行精准调控。研究表 明, 通过施加外场(电场、磁场、光场等)作用, 可以

(a)

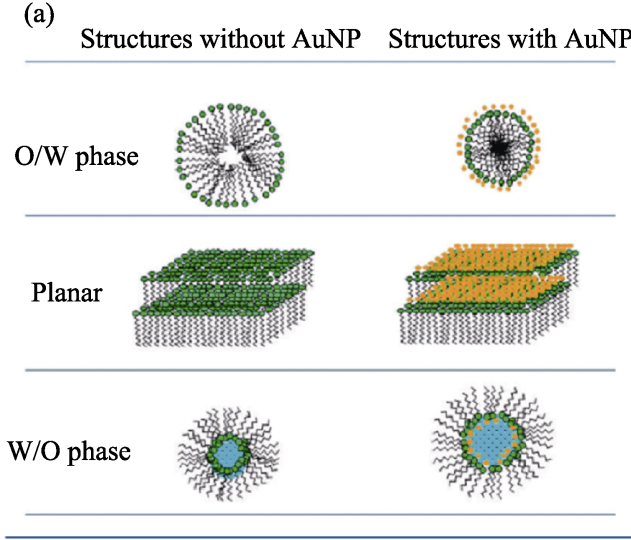

有效控制纳米粒子的自组装速度、组装位点以及排 列取向等等，实现定位乃至定向自组装 ${ }^{[33,47]}$ 。

\subsection{1电场诱导定位自组装}

外加电场可使极化纳米粒子形成链、胶体或晶

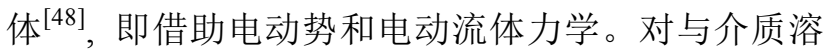
液接触的电极施加直流(DC)或交流(AC) 电压使不 同特性的纳米粒子和载体介质发生响应，从而影响 纳米粒子的自组装行为。采用不同的电场强度和频 率调控不同体系的自组装行为。其中, 粒子的极化 方式、移动电荷、固定电荷及其分布在电场诱导定 位自组装过程中起着重要作用 ${ }^{[49]}$ 。

Xiang 等 ${ }^{[50]}$ 通过电场诱导自组装的方法在硅 (111) 晶片上垂直定位组装多壁碳纳米管(MWCNTs) 阵列。通过控制直流电压 $(0 \sim 4 \mathrm{~V})$ 可以控制 MWCNTs 阵列的密度。在低压直流电场下, 通过 MWCNTs 末端羧基与硅电极表面羟基的缩合反应，可以得到 场发射性能优异的 MWCNTs 阵列。在此基础上, 该 研究团队利用电场诱导定位效应在柔性基板上定位 定向组装高密度单壁碳纳米管 $(\mathrm{SWCNTs})^{[51]}$, 将图 案化的 SWCNTs 组装在柔性聚对苯二甲酸乙二醇酯 (PET)基板上，这项技术对于功能材料的自组装行为 和精确定位具有重要意义。Huang 等 ${ }^{[2]}$ 研究了阴离子 铂配合物 $\left(\left[\mathrm{Pt}(\mathrm{tfmpy})(\mathrm{CN})_{2}\right] \mathrm{Bu}_{4} \mathrm{~N}^{+}, \mathrm{tfmpy}=2-(4-\right.$ 三氟甲 基苯基)吡啶)在自发自组装过程以及在电场驱动下 配合物组装形貌的变化情况。SEM 和 TEM 表征结 果显示, 配合物在两种组装过程中得到的形貌分别 为棒状和花状, 这是由于在自发自组装的棒状纳米 结构中, 相邻的铂配合物阴离子与四丁基铵盐阳离 子形成了两个离子的交替层, 而在电场驱动下通过 分子间 $\mathrm{Pt} \cdots \mathrm{Pt}$ 和 $\pi-\pi$ 堆积相互作用组装而形成花状 纳米结构(如图 6(b)所示)。另外, 他们还探究了不同 电压对纳米结构形貌的影响, 电极表面的粗䊁程度 是决定纳米结构形貌的关键因素。共聚焦苂光成像 和寿命成像结果显示, 由两种不同组装方法得到的

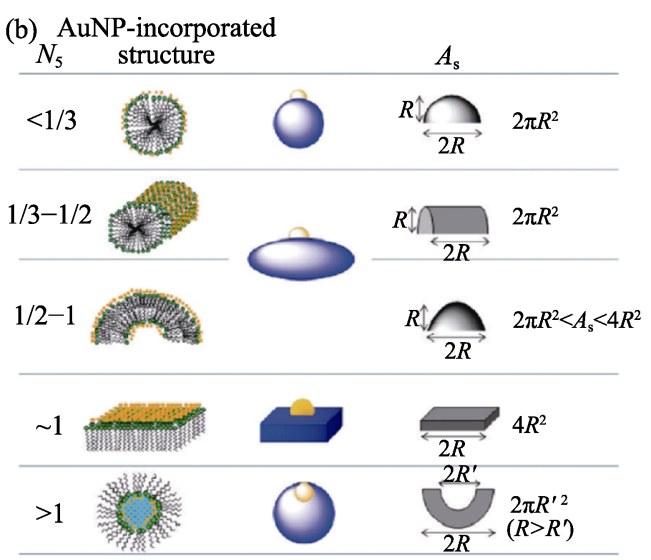

图 5 金纳米颗粒(AuNP)在不同相界面中对自组装尺寸的影响 ${ }^{[46]}$

Fig. 5 Effect of gold nanoparticles (AuNP) on self-assembly size in different phase interfaces ${ }^{[46]}$ 
(a)

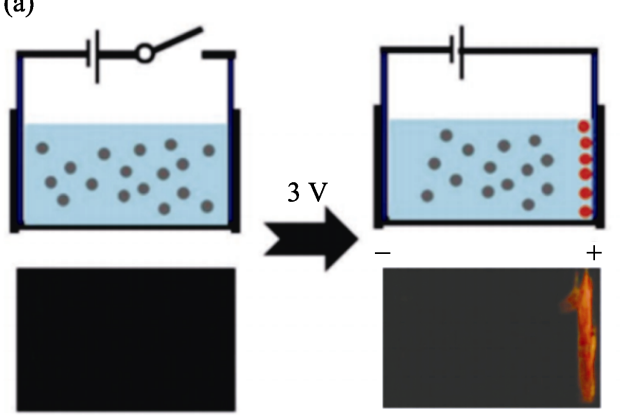

(b)

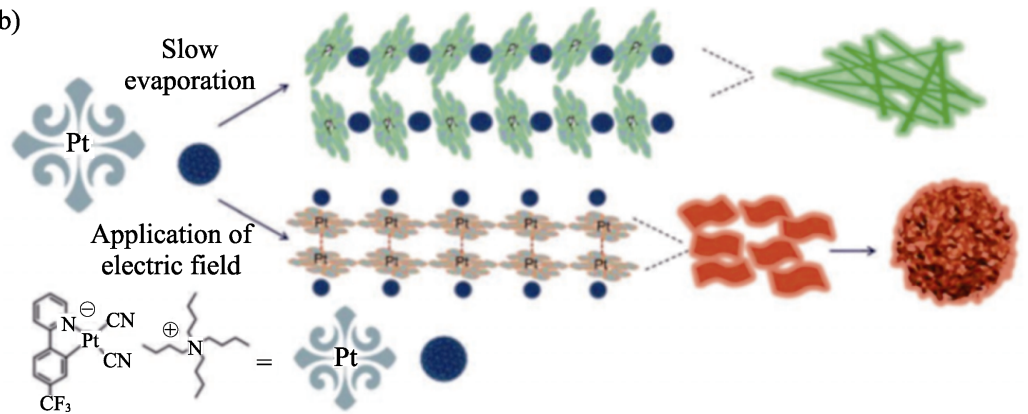

(c)

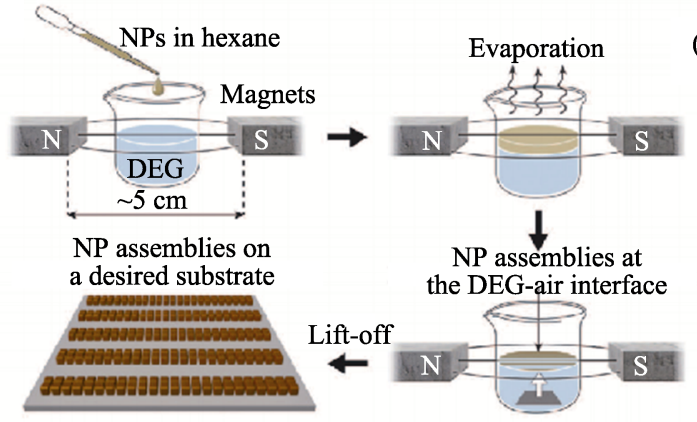

(d)

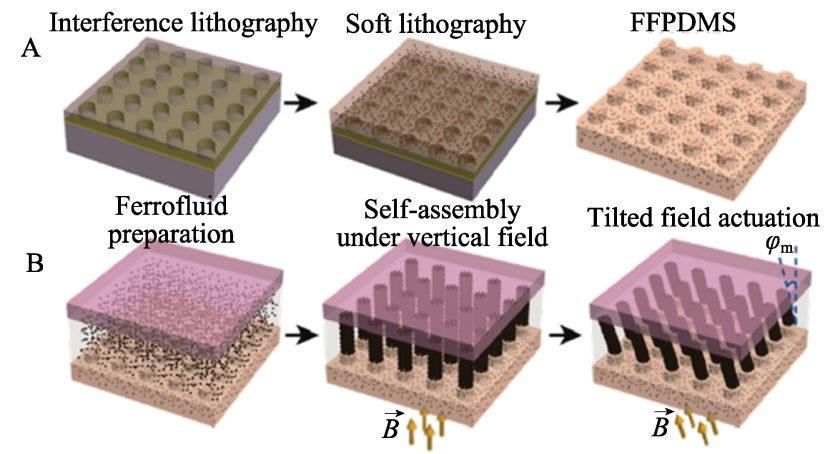

图 $6(a, b)$ 自发自组装和电场诱导自组装过程和不同形貌组装过程示意图 ${ }^{[52]},(\mathrm{c})$ 磁场诱导一维纳米立方体带 自组装示意图 ${ }^{[56]}$; (d)磁性纳米柱阵列(FFPDMS 柱阵列)诱导氧化铁纳米颗粒自组装示意图 ${ }^{[57]}$

Fig. 6 (a,b) Schematic diagram of self-assembly and electric field induced self-assembly and assembly process with different morphologies ${ }^{[52]}$; (c) Schematic diagram of magnetic field-induced self-assembly of one-dimensional nanocube belts ${ }^{[56]}$; (d) Schematic diagram of magnetic nanopillar array (FFPDMS column array) inducing self-assembly of iron oxide nanoparticles ${ }^{[57]}$

纳米材料具有不同的发光颜色和寿命，这种独特的 性质在数据存储、防伪和智能窗口等领域中具有潜 在的应用价值。

\subsection{2 磁场诱导定位自组装}

通常纳米材料的自组装通过非特异性相互作用 驱动, 例如范德瓦尔斯力和静电力等等。研究表明, 施加外部磁场是一种诱导纳米粒子之间长距离定向 相互作用的有效方法。除了外加磁场, 具有磁性的 纳米粒子也可以在内部磁力的驱动下进行自组装。 磁力可以克服纳米粒子之间的热运动和静电排斥作 用, 磁性纳米粒子在邻近的磁性粒子或外场等形成 的局部磁场的诱导下易于组装成纳米链、纳米线和 纳米棒等结构, 其中磁性粒子种类、大小和形状等 会影响其磁性能, 从而影响自组装效果 ${ }^{[53-54]}$ 。

Montero 等 ${ }^{[5]}$ 制备了一种具有微椭球形状和内 部结构高度各向异性的磁性二氧化硅纳米复合粒子, 这些微粒是由各向异性的磁性纳米粒子自组装在二 氧化硅基质中。由于这种独特的结构, 它们呈现出 强大的单个磁矩, 当它们悬浮在水中时, 在没有外 部磁场的情况下也能自组装成链。Klajn 等 ${ }^{[56]}$ 利用 磁场对立方磁性纳米晶在气一液界面的组装进行调 控, 制备了磁性颗粒一维单螺旋、双螺旋和三螺旋 等复杂结构(图 6(c)), 并通过模拟, 证明制备的螺旋 结构是粒子间范德华力、偶极相互作用以及熵等因
素协同作用的结果。在外加磁场的作用下, 磁性颗 粒会沿着磁场方向组装为单粒子排布的一维链状结 构, 随着溶剂的蒸发, 单粒子链继续聚集, 在气一液 界面进一步组装成复杂的纳米晶超结构。Chang 等 ${ }^{[57]}$ 报道了一种具有动态着色和虹彩的可磁调谐纳米结 构材料, 当在液体环境中磁化时, 以周期性排列的 磁性纳米柱阵列(FFPDMS 柱阵列)为模板诱导氧化 铁纳米颗粒自组装。磁性模板诱导的周期性局部磁 场针定组装好的颗粒柱, 当外加磁场的角度发生变 化时，可以使结构在基底上产生倾斜。所制备的结 构显示出从绿色到黄色的可逆色位移高达 $192 \mathrm{~nm}$ (图 6(d))。这种方法可改变周期结构的取向, 为可调 谐磁结构和动态光子器件提供了潜在的应用。

\section{4 其他}

\subsection{1 光诱导自组装}

光场诱导仿生自组装也是常用的外场力, 在光 驱动下可直接使用具有功能基团的单体进行特定位 点反应, 为设计稳定的功能化纳米材料提供新的设 计思路。光诱导一般依赖于光照下纳米颗粒表面光 敏配体的异构化, 例如, 带有螺吡喃官能团的配体 会进行开环异构化，而带有偶氮苯官能团的配体在 紫外光照射下也会发生异构化现象。

$\mathrm{Li}$ 等 ${ }^{[58]}$ 报道了一种光诱导的聚(乙二醇)-block聚 $(o$-硝基苯基-谷氨酸)二元嵌段共聚物。该共聚物 
在水溶液中自组装成胶束微球, 经过紫外线照射后 会转变为圆柱体(图 7(a)), 是由于共聚物侧链上的 $o$-硝基苯基团在紫外光照射下发生裂解, 破坏了两 亲结构, 从而引发了形态变化。另外, 通过添加金属 离子, 可以诱导组装获得不同尺寸的分层纳米结 构。这种在光和金属离子双重诱导下的自组装方法 为生物聚合物材料的制备提供了新思路, 也可用于 智能水凝胶和药物释放等领域。Tan 等 ${ }^{[59]}$ 研发了一 种光调控聚合诱导自组装方法(Photo-PISA), 首先 通过 Photo-PISA 在室温下制备负载辣根过氧化物 酶 (HRP) 的 mPEG-PHPMA 囊泡, 然后分别以 mPEG-PHPMA 囊泡和异丙基丙烯酰胺(NIPAM)为 种子, 通过 Photo-PISA 法制备负载 HRP 的 mPEG-PHPMA-PNIPAM 囊泡(图 7(b))。通过 $N, N^{\prime}-$ 二甲基丙烯酰胺(DMA)或双丙酮丙烯酰胺(DAAM)
与 NIPAM 共聚可改变聚合物囊泡的响应温度, 可 用于制备酶催化纳米反应器。目前, 聚合物纳米结 构大多是通过经典的后组装策略进行制备, 如何实 现聚合物原位自组装也是当前研究的热点。Yan 等 ${ }^{[0]}$ 提出了光诱导原位自组装方法(Light-initiated in situ self-assembly), 即多个均聚物可以通过光化学耦合 重新形成各种纳米结构,其合成过程如图 7(c)所示。 通过调整均聚物的初始成分或预设光参数, 可以预 测和再现各种纯聚合物的形貌。光诱导原位自组装 方法依赖于光化学耦合和自组装过程, 为纳米结构 原位自组装提供新的合成策略。

\subsection{2 基于羟基氢键驱动的分相自组装}

氢键为正向极化的氢原子与相邻原子的负电荷 的强相互作用。氢键存在于核酸碱基对、蛋白质中 的氨基羟基和高分子链中, 其作用力远超分子间静 (a)
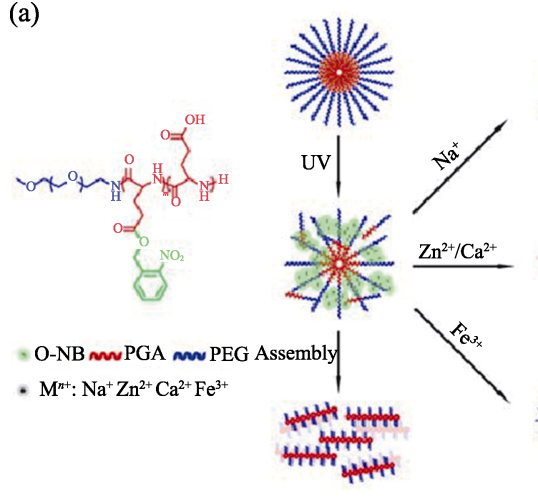

(b)

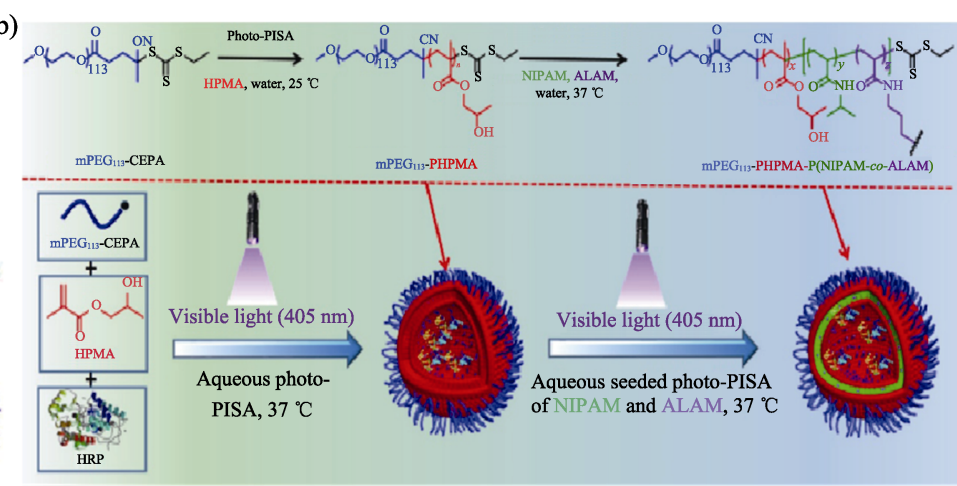

(c)

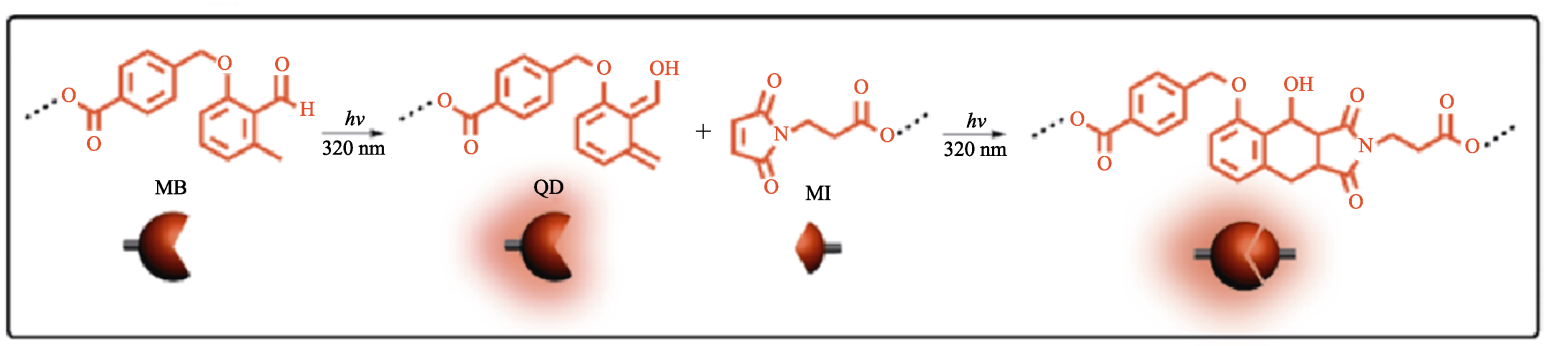

PCL-MI increase
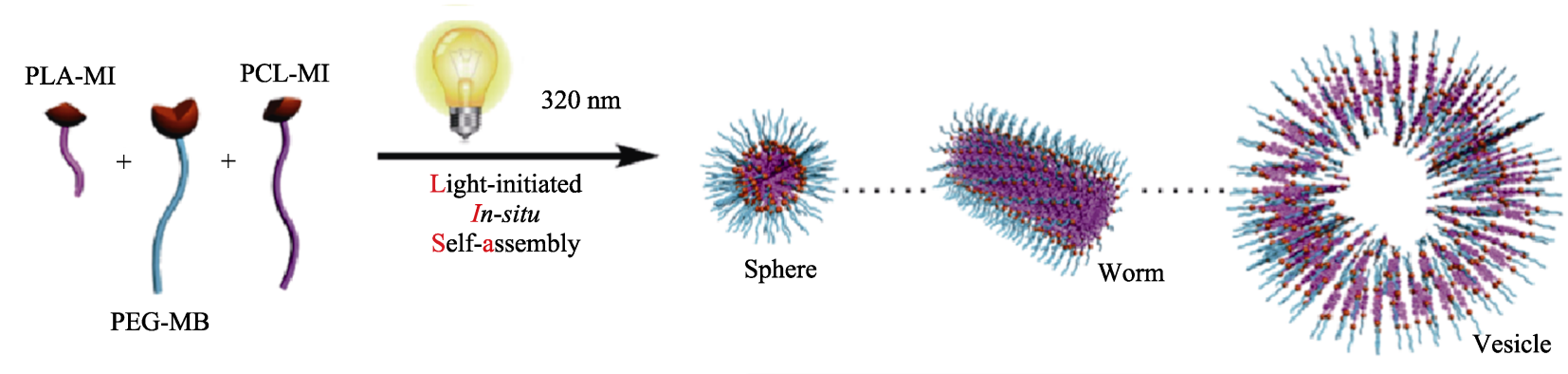

PLA-MI increase

图 7 (a)光和金属离子诱导自组装和重组装示意图 ${ }^{[58]}$, (b)通过种子 Photo-PISA 制备负载 HRP 的 温敏聚合物囊泡 ${ }^{[59]},(\mathrm{c})$ 光诱导原位自组装合成聚合物纳米结构 ${ }^{[60]}$

Fig. 7 (a) Schematic diagram of self-assembly and reassembly induced by light and metal ions ${ }^{[58]}$;

(b) Preparation of HRP-loaded temperature-sensitive polymer vesicles by seed Photo-PISA ${ }^{[59]}$;

(c) Light-induced in-situ self-assembly synthesis of polymer nanostructures ${ }^{[60]}$ 
(a)

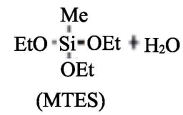

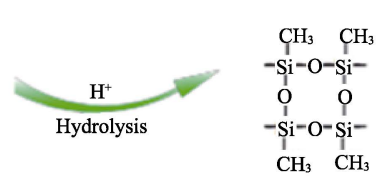

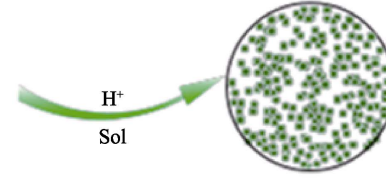

Multiphase dispersive system

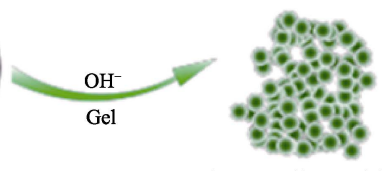

Polyorganosiloxane $\left(\mathrm{SiO}_{2}\right)$

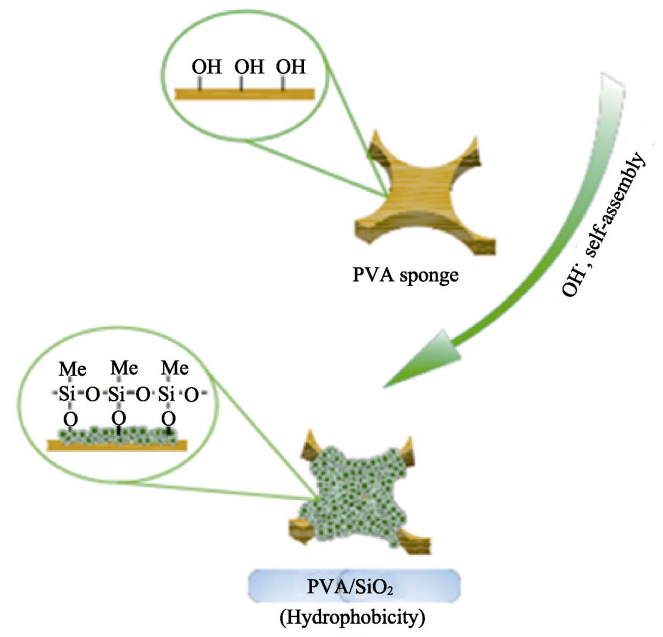

(c)

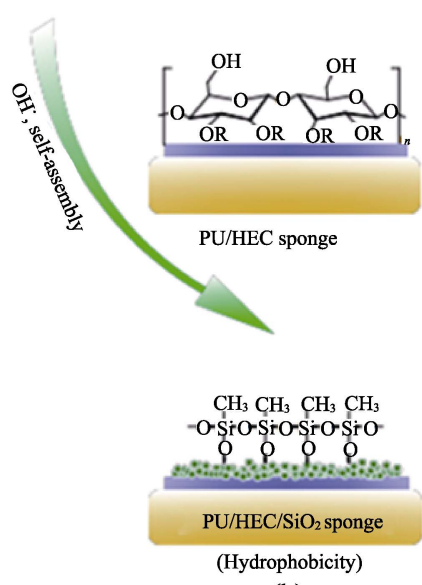

(b)

图 8 (a)采用溶胶一凝胶法水相制备疏水聚硅氧烷过程示意图 ${ }^{[61]}$, (b) 羟基氢键诱导自组装制备三元复合物疏水聚氨酯绵 $\mathrm{PU} / \mathrm{HEC} / \mathrm{SiO}_{2}$ 过程示意图 ${ }^{[61]}$, (c)羟基氢键诱导自组装疏水聚乙烯醇绵 $\mathrm{PVA} / \mathrm{SiO}_{2}$ 过程示意图 ${ }^{[62]}$

Fig. 8 (a) Preparation of hydrophobic polysiloxane in aqueous phase by Sol-Gel method ${ }^{[61]}$; (b) Schematic diagram of preparation of ternary composite hydrophobic polyurethane sponge $\mathrm{PU} / \mathrm{HEC} / \mathrm{SiO}_{2}$ by hydroxyl hydrogen bond induced self-assembly ${ }^{[61]}$;

(c) Schematic diagram of PVA $/ \mathrm{SiO}_{2}$ with hydrophobicity induced by hydroxyl hydrogen bond ${ }^{[62]}$

电作用，是生命体中实现分子识别和仿生自组装策 略中重要的非共价键作用力。基于氢键的分子识别 作用，在多相溶液中实现组装体仿生自组装。

氢键自组装体一般只能在低极性溶剂中稳定存 在，如何在强极性溶剂特别是水相中生成氢键诱导的 稳定自组装体, 一直是化学领域中极具挑战的问题, 在生命科学领域则是生命起源探索的核心问题之一。

Xiang 等 ${ }^{[61]}$ 提出了分相自组装的新策略, 首次 由单一水相成功获得了超疏水自组装体。该团队以 甲基三乙氧基硅烷 (MTES) 为前驱体, 水为唯一溶 剂, 采用溶胶一凝胶法, 通过酸碱两步催化合成了一 系列具有不同形貌的聚甲基硅氧烷聚合物(图 8(a,b))。 在酸催化作用下, MTES 单体可以在油、水两相界面 逐步水解转变为亲水性分子, 然后自组装为初级溶 胶粒子，在水相中形成稳定的多相分散体系; 然后 在浓碱催化下, 溶胶粒子迅速聚集、长大并从水相 中析出, 形成具有三维网络骨架的疏水气凝胶; 进 一步借助聚氨酯表面等型覆盖的羟乙基纤维素 (HEC)表面羟基氢键引力, 促使聚硅氧烷凝胶粒子 在材料表面进行自组装, 形成低表面能的覆盖层, 获得理想的表面粗糙度。材料从亲水向疏水转变, 同时保留了高孔隙率结构。

此外，该团队以聚乙烯醇绵为基材，以 MTES 为修饰单体进行原位自组装合成了二元复合疏水聚
乙烯醇绵 ${ }^{[62]}($ 图 8(a,c)), 聚乙烯醇绵表面的羟基为硅 氧烷的原位聚合提供了活性位点，可以使聚甲基硅 氧烷对聚乙烯醇绵三维骨架孔道进行等型覆盖, 保 持了聚乙烯绵的多孔结构, 形成了稳定的二元复合 结构。等型覆盖降低了孔道表面自由能, 增加了表 面粗糙度, 修饰后的聚乙烯醇绵表面具有优异的超 疏水性能。

\section{2 仿生自组装纳米材料的应用}

\section{1 传感器}

研究纳米尺度自组装为微型电子元器件的制备 提供了技术保障 ${ }^{[63]}$, 由此得到的电子元器件具有更 高的选择性和灵敏性, 能够节约材料, 降低成本。过 去几十年里已有大量关于仿生自组装应用于温度和 $\mathrm{pH}$ 传感器 ${ }^{[64-66]}$ 、生物和化学传感器 ${ }^{[67-70]}$ 以及等离子 尺 $^{[71-73]}$ 等方面的报道, 近年来自组装传感器依旧是 相关领域的研究热点。

Zhang 等 ${ }^{[74]}$ 报道了以柔性聚酰亚胺为祄底(图 9(a)), 通过逐层自组装方法制备的基于 $\mathrm{SnS}_{2} / \mathrm{Zn}_{2} \mathrm{SnO}_{4}$ 杂化 膜的柔性湿度传感器, 具有响应速度快、重复性好 和室温下稳定性好等优点。不同于静电纺丝法 ${ }^{[75]}$ 和 水热法 ${ }^{[76]}$ 等制备的 $\mathrm{Zn}_{2} \mathrm{SnO}_{4}$ 化学传感器(回收率低、 室温下灵敏度低), 自组装法制备的传感器能够促 


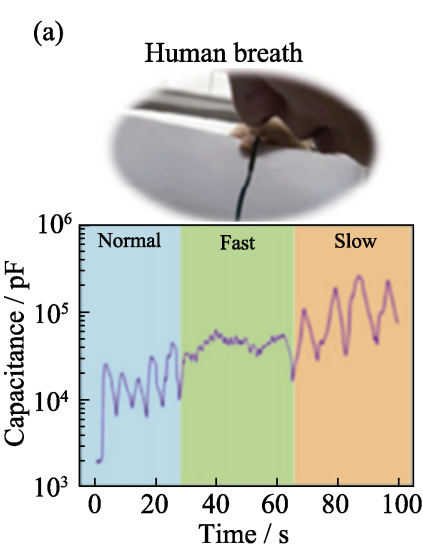

Baby diaper wet monitor

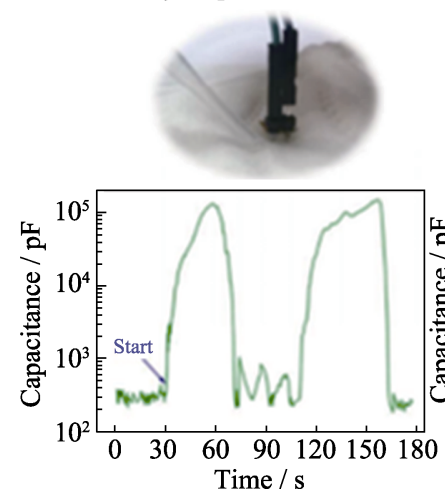

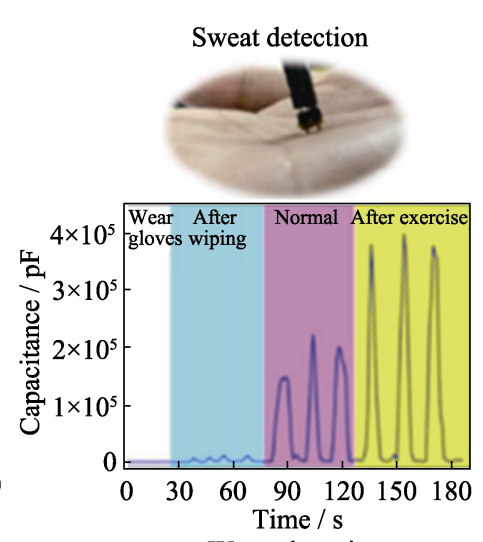

Water dropping
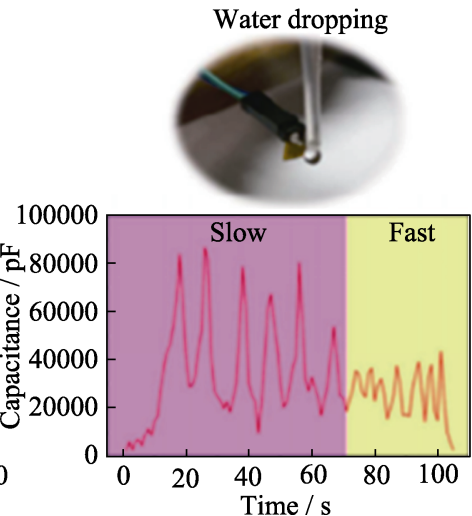
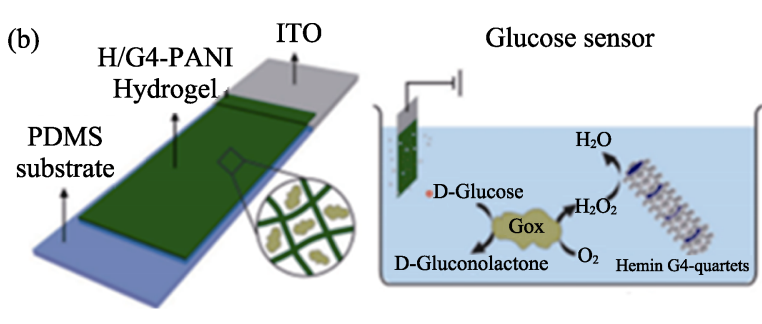

(c)
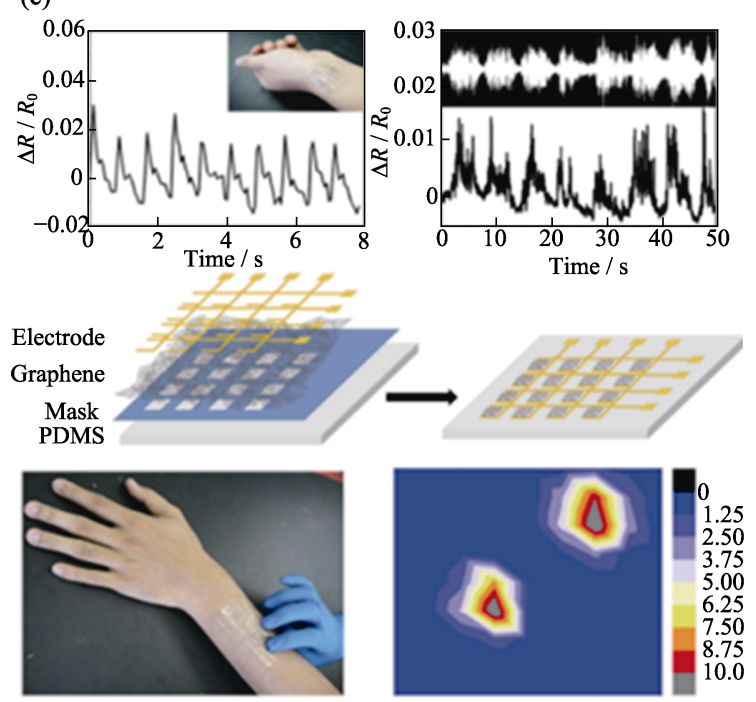

图 9 (a) $\mathrm{SnS}_{2} / \mathrm{Zn}_{2} \mathrm{SnO}_{4}$ 混合膜传感器的传感性能: 人呼气、手掌出汗和婴儿尿布上的尿液及水滴计数 ${ }^{[74]}$, (b) 基于 $\mathrm{GO}_{x}$ 装载的 $\mathrm{H} / \mathrm{G} 4-\mathrm{PANI}$ 水凝胶的葡萄糖传感器检测葡萄糖 ${ }^{[85]},(\mathrm{c})$ 人体皮肤上的应变传感器阵列的实时响应 ${ }^{[83]}$

Fig. 9 (a) $\mathrm{SnS}_{2} / \mathrm{Zn}_{2} \mathrm{SnO}_{4}$ hybrid membrane sensor performance under different applications: human exhalation, palm sweating, urine and water droplets on baby diapers ${ }^{[74]}$; (b) Glucose sensor based on $\mathrm{GO}_{x}$ loaded H/G4-PANI hydrogel for detecting glucose ${ }^{[85]}$; (c) Real-time response of strain sensor arrays on human skin ${ }^{[83]}$

进 $\mathrm{Zn}_{2} \mathrm{SnO}_{4}$ 作为气敏元件的应用 ${ }^{[77]}$ 。Chang 等 ${ }^{[78]}$ 将 常规荧光基团萠和吡啶引入配位驱动的自组装金属 环, 由此材料的硅支撑薄膜对气态胺显示出传感特 性。He 等 ${ }^{[79]}$ 通过滑石粉和有机染料分子的气液界面 自组装成膜, 研究了自组装复合膜在不同气体下的 颜色可逆变化和气体响应, 为功能性自组装膜的气 体传感器和化学开关提供了新的思路。

Rossi 等 ${ }^{[80]}$ 报道了用于磁力传感器的自组装 $\mathrm{GaAs}$ 纳米线, 与传统方法获得的机械力传感器相 比尺寸更小, 灵敏度 ${ }^{[81]}$ 和分辨率 ${ }^{[82]}$ 更高。有研究团 队采用不同自组装基元制备了多种类型的传感器, 如用于电子皮肤和可穿戴传感器等的石墨烯应力传 感器 ${ }^{[83]}$ (图 9(c)), 苂光有机纳米粒子铁(III)传感器 ${ }^{[84]}$, 灵活的葡萄糖生物传感器 ${ }^{[85]}$ (图 9(b)), 以及用于特 定氨基酸电化学识别的手性传感装置 ${ }^{[86]}$ 等。

\section{2 表面增强拉曼散射}

与单个金属纳米粒子相比, 组装体由于耦合作 用引起电磁场局部增强, 形成的拉曼散射强度高达 六个数量级, 具有更高的表面增强拉曼散射 $(\mathrm{SERS})^{[87]}$, 是强有力的化学和生物传感现象 ${ }^{[88]}$ 。Ma
等 ${ }^{[89]}$ 制备了由金纳米颗粒在环已烷/水界面处自组 装形成的表面增强拉曼平台，用于农药残留量检 测。在环已烷/水双相界面, 以亲水性十六烷基三甲 基溴化铵包覆的金纳米棒为自组装基元，形成的二 维阵列能极大地增强 SERS, 由此获得的便携式拉 曼光谱仪可以检测人体尿液中极低含量的甲基苯丙 胺，为毒品的快速侦查提供帮助 ${ }^{[90]}$ 。此外还有金纳 米粒子组装胶带, 可用于检测鱼表面残留的孔雀石 绿 ${ }^{[91]}$; 金/银纳米球自组装单分子膜可检测三苯基 甲烷染料 ${ }^{[92]}$; 采用银/氧化亚铜自组装纳米复合薄 膜制作非酶电化学 $\mathrm{H}_{2} \mathrm{O}_{2}$ 传感器 ${ }^{[93]}$ 。

强的 SERS 效应主要集中于 $\mathrm{Au}^{[94]} 、 \mathrm{Ag}^{[95]}$ 和 $\mathrm{Cu}$

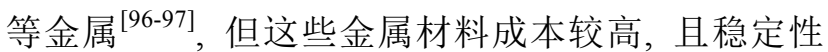
不理想 ${ }^{[98]}$, 生物相容性差 ${ }^{[99]}$, 急需替代 SERS 的材 料 ${ }^{[100]}$ 。Lan 等 ${ }^{[101]}$ 报道了基于石墨烯量子点和 $\mathrm{Mn}_{3} \mathrm{O}_{4}$ 的自组装复合材料, 具有较好的 SERS 效应。Yi 等 ${ }^{[102]}$ 开发了基于紧密堆积的 $\mathrm{SiO}_{2}$ 球形颗粒实现 SERS 的 技术, 在表面化学、生物学和微电子学等领域都有 潜在的应用。除传统材料外, 新型二维层状材料 $M X e n e^{[103]}$ 同样可以用于 SERS。Chen 等 ${ }^{[104]}$ 研究了 
磺胺酸改性 MXene，显示出其潜在 SERS 应用价值。

\section{3 生物医疗}

自组装技术也为生物医疗提供了新的发展方向, 多种材料有望通过仿生自组装用于药物传递、蛋白

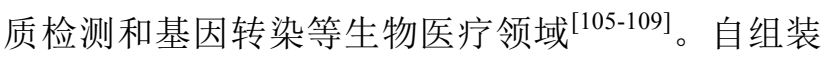
也常用于制造人造骨骼和牙齿，如以蛋清蛋白为表 面活性剂，通过生物矿化过程自组装合成羟基磷灰

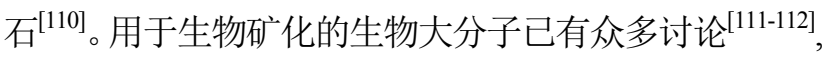
其中多肽 ${ }^{[113-114]}$ 及其衍生物, 由于其优良的生物相 容性、合成的简便性和结构的多变性决定了其在生 物医疗领域的广泛应用。

有研究报道, 在精氨酸-丙氨酸-天冬氨酸-丙氨 酸(Arg-Ala-Asp-Ala，RADA4)和异亮氨酸-赖氨酸-烦 氨酸-丙氨酸-缬氨酸(Ile-Lsy-Val-Ala-Val, IKVAV)之 间插入甘氨酸(Gly)和丝氨酸(Ser), 自组装形成的新 型三维支架(RADA4GGSIKVAV, R-GSIK) 可用作细
胞培养的支架。与常规培养方法相比, R-GSIK 更能 促进细胞的黏附、繁殖和迁移, 在细胞治疗和神经 元修复方面有广泛的应用前景 ${ }^{[115]}$ 。Myriam 等 ${ }^{[116]}$ 报道了可逆肽自组装，可用来调控体内天然肽激素 的活性。通过模仿高抗菌活性、低毒性的抗菌肽 AMP 的特性，科研人员设计了具有简单序列和结构 的两亲性肽，表现出明显的抗菌和抗肿瘤活性，并表 明抗菌活性与设计分子自组装形成的形状有关 ${ }^{[117-119]}$ 。 结合肽自组装和酶催化, 研究人员还设计了能够在 水溶液中自组装形成纳米带的两亲性短肽, 加入转 谷氨酸酶(TGase)后, 肽溶液会形成刚性凝胶 ${ }^{[120]}$, 出血时血液中的凝血因子被凝血酶转化为活性 TGase，可用于止血(图 10(a))。多肽的衍生物，例如 多肽与二酰亚胺类苂光分子的共价结合形成的复合 分子，可作为新型的细胞荧光探针，用于细胞成像 技术、跟踪和定位癌细胞等领域(图 10(b) $)^{[121-122]}$ 。 (a)

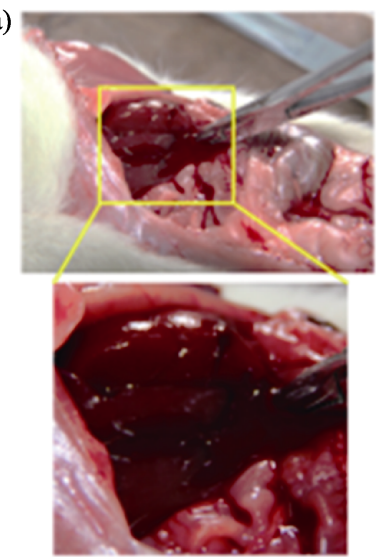

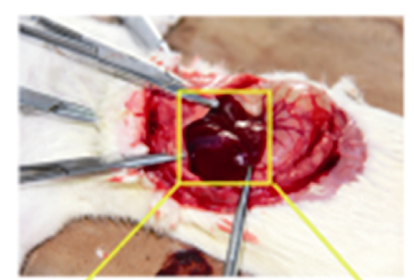

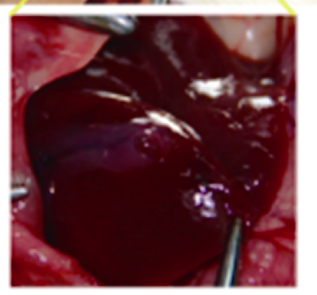

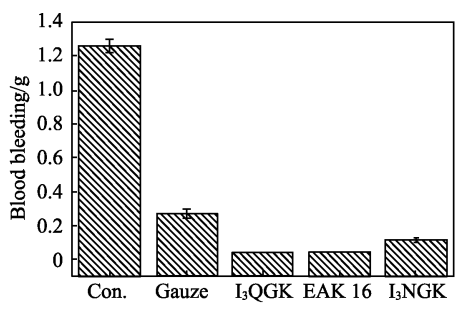

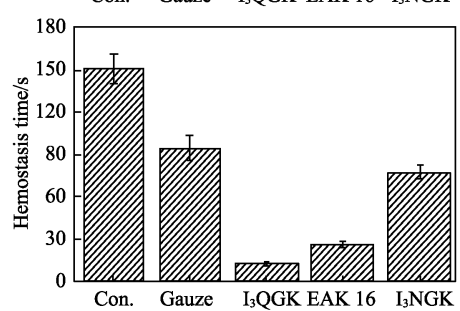

(b)
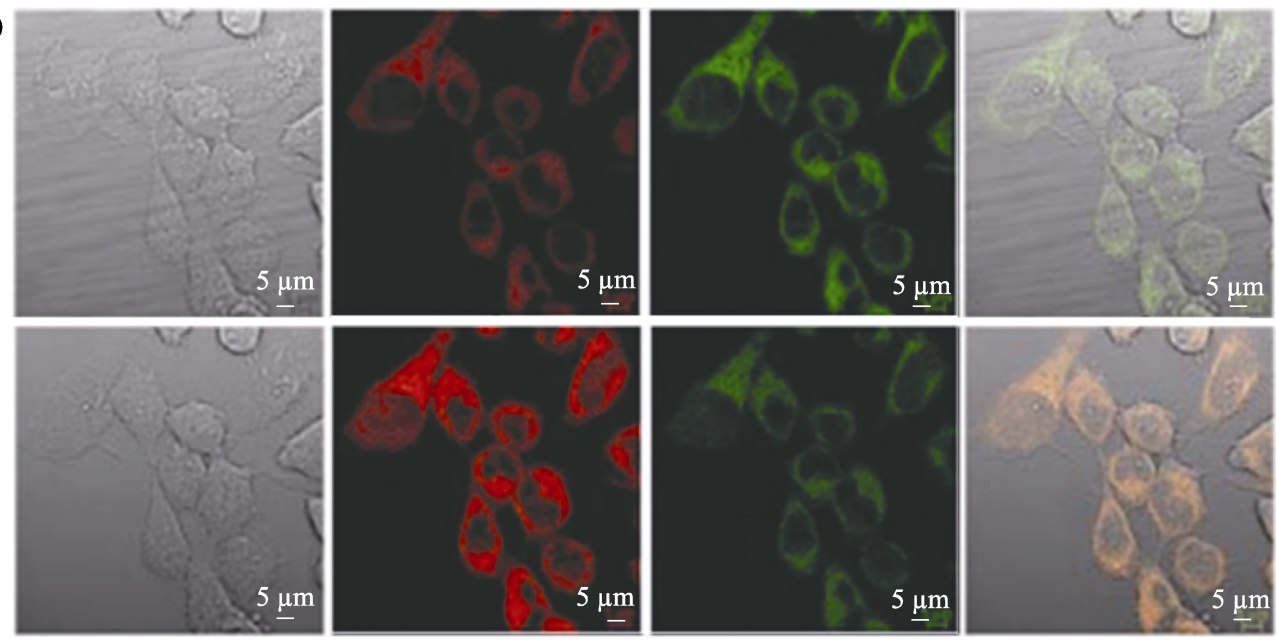

图 10 (a)大鼠肝止血: 左为肝脏在左叶矢状切开后未进行任何处理而产生大量出血(对照组), 右为使用约 $1 \%(w / v)(16 \mathrm{mmol} / \mathrm{L})$ 的 I3QGK 水溶液治疗导致快速止血 $\left(\mathrm{I}_{3} \mathrm{QGK} \text { 组 }\right)^{[120]}$;

(b)用单光子激光扫描共聚焦显微镜观察 PC-3 细胞中的自组装肽 ${ }^{[122]}$

Fig. 10 (a) Rat liver hemostasis. Left: Liver produced massive bleeding after sagittal incision in the left lobe (Con. group). Right: Treatment with approximately $1 \%(w / v)(16 \mathrm{mmol} / \mathrm{L})$ I3QGK aqueous solution leads to rapid hemostasis $\left(\mathrm{I}_{3} \mathrm{QGK}\right.$ group ${ }^{[120]}$. (b) Single-photon laser scanning confocal microscope images for self-assembling peptides in PC-3 cells ${ }^{[122]}$ 


\section{4 其他}

纳米仿生自组装材料的应用除了上述之外, 还 可用在 $\mathrm{CdSe}$ 纳米棒组装阵列 ${ }^{[123-124]}$ 以及 $\mathrm{CdSe}$ 纳米 棒的低成本无毒替代品 ${ }^{[125]}$, 在光伏器件领域也有 很好的应用。通过调节自组装材料和自组装条件, 可自组装形成特定的结构, 如肽自组装纳米棒形成 的分形结构 ${ }^{[126]}$, 控制油水界面 $\mathrm{CaCO}_{3}$ 晶体自组装 形貌 ${ }^{[127]}$ 等。可利用自组装形成的特定纳米结构(如 纳米管)作为模板生产银纳米线 ${ }^{[128]}$ 。在电化学方面, 在氧化还原过程中自组装金属纳米粒子具有高活性 界面 ${ }^{[129-130]}$ 。利用羟基氢键诱导自组装可以制备疏 水性能优异的高效、连续分离的油水分离材料, 如 三元复合疏水聚氨酯海绵最高可吸收自身重量 75 倍的油品 ${ }^{[61]}$, 疏水化修饰后的聚乙烯醇绵在外加真 空系统辅助下可实现连续油水分离 ${ }^{[62] 。}$

\section{3 纳米材料仿生自组装技术总结和}

\section{展望}

有关纳米材料自组装的研究不断取得进展, 并 在众多领域展现出广阔的应用前景，但仍然面临诸 多挑战。本文主要归纳了纳米材料仿生自组装的相 关研究进展及其应用前景。在屏蔽效应作用下，祄底 表面不同化学键/基团对修饰单体的作用力不同, 导 致键合作用的差异, 可实现纳米粒子位相定位自组 装。在双相界面自组装中, 基于双液相表面能的差异, 可诱导纳米粒子在双相界面组装成不同形貌的纳米 材料。利用外场作用控制纳米材料组装过程, 也是实 现对组装结构精确调控的有效方式, 在电场、磁场和 光场等的驱动下，纳米粒子可实现定向移动，从而 实现纳米材料的定向自组装。氢键是一种介于共价 键与范德瓦尔斯力之间的特殊作用力, 有加强分子间 力的作用，使分子间以特定的结构结合，再协同分 子间其它相互作用(如电荷转移等)实现纳米粒子自 组装, 可进行一系列材料表面改性和形貌优化。

精确可控、定位组装的纳米材料组装一直是研 究热点, 但是由于组装驱动力的不可控以及组装单 元的多分散性, 组装结构通常存在长程无序、难以避 免组装缺陷等问题。因此, 纳米材料的大面积精准组 装仍然是目前面临的巨大挑战, 这也阻碍了其在高 性能器件制备中的应用。纳米材料的仿生自组装主 要研究方向和发展前景主要在以下三个方面:

1)进一步深入研究纳米材料自组装的基础理论, 建立系统的有助于组装不同形貌、类型及特定功能 的纳米材料, 拓展新型组装单元的合成路径。深入探
索纳米粒子在多相界面或复杂的三维体系中实现精 准定位组装。

2)研究特定结构纳米材料的仿生自组装的规律 和机理，进而自主设计非天然的具有特定结构的自 组装单体。研究自组装过程中的仿生表面或界面的 自组装行为, 可用于精确制备具有特定形貌和图案 的纳米级精细结构。

3)将自组装技术用于具有特定功能的仿生器件 和微体系中，如自组装制备的微胶囊，通过对胶囊 表面进行分子识别修饰、特殊结构设计等, 形成简单 的细胞体系, 不仅可用在药物传递、药物缓释等方面, 也可用于各种传感器甚至生物智能器件的设计等。

\section{参考文献:}

[1] VALIEV R. Materials science-nanomaterial advantage. Nature. 2002, 419(6910): 887-889.

[2] SEKER U O S, CHEN A Y, CITORIK R J, et al. Synthetic biogenesis of bacterial amyloid nanomaterials with tunable inorganic-organic interfaces and electrical conductivity. ACS Synthetic Biology, 2016, 6(2): 266-275.

[3] KOVALCHUK A A, TOUR J M. Tuning electrical conductivity of inorganic minerals with carbon nanomaterials. ACS Appl. Mater. Interfaces, 2015, 7(47): 26079-26084.

[4] FAN J A, WU C, BAO K, et al. Self-assembled plasmonic nanoparticle clusters. Science, 2010, 328(5982): 1135-1138.

[5] NA, ZHANG S, WANG S, et al. A catalytic nanomaterial-based optical chemo-sensor array. J. Am. Chem. Soc., 2006, 128(45): 14420-14421.

[6] DE OLIVEIRA R E P, SJDIN N, FOKINE M, et al. Fabrication and optical characterization of silica optical fibers containing gold nanoparticles. ACS Appl. Mater. Interfaces, 2015, 7(1): 370-375.

[7] KWON O S, SONG H S, PARK $\mathrm{T} \mathrm{H}$, et al. Conducting nanomaterial sensor using natural receptors. Chem. Rev., 2019, 119(1): $36-93$.

[8] KULKARNI G S, REDDY K, ZHONG Z, et al. Graphene nanoelectronic heterodyne sensor for rapid and sensitive vapour detection. Nat. Commun., 2014, 5(1): 4376-4382.

[9] BOUBENIA S, DAHIYA A S, POULIN-VITTRANT G, et al. A facile hydrothermal approach for the density tunable growth of $\mathrm{ZnO}$ nanowires and their electrical characterizations. Sci. Rep., 2017, 7(1): 15187 .

[10] NING L, LI Y, LI W, et al. One-step hydrothermal synthesis of $\mathrm{TiO}_{2} @ \mathrm{MoO}_{3}$ core-shell nanomaterial: microstructure, growth mechanism, and improved photochromic property. Journal of Physical Chemistry C, 2016, 120(6): 3341-3349.

[11] POMERANTSEVA E, BONACCORSO F, FENG X, et al. Energy storage: the future enabled by nanomaterials. Science, 2019, 
366(6468): eaan 8285 .

[12] ZHOU Y, NASH P, LIU T, et al. the large scale synthesis of aligned plate nanostructures. Sci. Rep., 2016, 6(1): 29972.

[13] SAI H, XING L, XIANG J, et al. Flexible aerogels based on an interpenetrating network of bacterial cellulose and silica by a non-supercritical drying process. J. Mater. Chem. A, 2013, 1(27): $7963-7970$.

[14] JOHN D, MACKENZIE E, BESCHER P, et al. Chemical routes in the synthesis of nanomaterials using the Sol-Gel process. Acc. Chem. Res., 2007, 40(9): 810-818.

[15] HAN C, ANDERSEN J, PILlAI S C, et al., Chapter green nanotechnology: development of nanomaterials for environmental and energy applications. In sustainable nanotechnology and the environment: advances and achievements. J. Am. Chem. Soc., 2013, 1124: $201-229$.

[16] ZARUR A J, YING J Y. Reverse microemulsion synthesis of nanostructured complex oxides for catalytic combustion. Nature, 2000, 403(6765): 65-67.

[17] GRESCHNER A A, BUJOLD K E, SLEIMAN H F. Intercalators as molecular chaperones in DNA self-assembly. J. Am. Chem. Soc., 2013, 135(30): 11283-11288.

[18] SHAO Y, JIA H, CAO T, et al. Supramolecular hydrogels based on DNA self-assembly. Acc. Chem. Res., 2017, 50(4): 659-668.

[19] SUN H, LUO Q, HOU C, et al. Nanostructures based on protein self-assembly: from hierarchical construction to bioinspired materials. Nano Today, 2017, 14: 16-41.

[20] AKASOV R, GILEVA A, ZAYTSEVA-ZOTOVA D, et al. 3D in vitro co-culture models based on normal cells and tumor spheroids formed by cyclic RGD-peptide induced cell self-assembly. Biotechnology Letters, 2016, 39(1): 45-53.

[21] WAQAS M, JEONG W J, LEE Y J, et al. PH-dependent in-cell self-assembly of peptide inhibitors increases the anti-prion activity while decreasing the cytotoxicity. Biomacromolecules, 2017, 18: 943-950.

[22] TRIFONOV A, STEMMER A, TEL-VERED R. Power generation by selective self-assembly of biocatalysts. ACS Nano, 2019, 13(8): $8630-8638$.

[23] DONG B, ZHOU T, ZHANG H, et al. Directed self-assembly of nanoparticles for nanomotors. ACS Nano, 2013, 7(6): 5192-5198.

[24] CHENG J Y, SANDERS D P, TRUONG H D, et al. Simple and versatile methods to integrate directed self-assembly with optical lithography using a polarity-switched photoresist. ACS Nano, 2010, 4(8): 4815-4823.

[25] ZHANG S G. Fabrication of novel biomaterials through molecular self-assembly. Nat. Biotechnol., 2003, 21(10): 1171-1178.

[26] CHEN X, QIAN W, JIN P, et al. Self-assembly of large DNA origami with custom-designed scaffolds. ACS Appl. Mater. Interfaces, 2018, 10(29): 24344-24348.

[27] YANG W, LI B. Facile fabrication of hollow silica nanospheres and their hierarchical self-assemblies as drug delivery carriers through a new single-micelle-template approach. J. Mater. Chem. $B, 2013, \mathbf{1 ( 1 9 ) : ~ 2 5 2 5 - 2 5 3 2 . ~}$

[28] GRÖSCHEL H A, MÜLLER A H E. Self-assembly concepts for multicompartment nanostructures. Nanoscale, 2015, $\mathbf{7 ( 2 8 ) :}$ 11841-11876.

[29] WALT D R. Top-to-bottom functional design. Nat. Mater, 2002. 1(1): $17-18$.

[30] MAI W, ZUO Y, ZHANG X, et al. A versatile bottom-up interface self-assembly strategy to hairy nanoparticle-based 2D monolayered composite and functional nanosheets. Chem. Comm., 2019, 55: 10241-10244

[31] MAJETICH S A, WEN T, BOOTH R A. Functional magnetic nanoparticle assemblies: formation, collective behavior, and future directions. ACS Nano, 2011, 5(8): 6081-6084.

[32] XIANG J, MASUDA Y, KOUMOTO K. Fabrication of super-site-selective $\mathrm{TiO}_{2}$ micropattern on a flexible polymer substrate using a barrier-effect self-assembly process. Adv. Mater., 2004, 16(16): 1461-1464.

[33] HUANG Z, WANG P C, MACDIARMID A G, et al. Selective deposition of conducting polymers on hydroxyl-terminated surfaces with printed monolayers of alkylsiloxanes as templates. Langmuir, 2005, 13: 6480-6484.

[34] KOBAKU S P R, KWON G, KOTA A K, et al. Wettability engendered templated self-assembly (wets) for fabricating multiphasic particles. ACS Appl. Mater. Interfaces, 2015, 7(7): 4075-4080.

[35] ZHAO B. Surface-directed liquid flow inside microchannels. Science, 2001, 291(5506): 1023-1026.

[36] XIANG J, ZHU P, MASUDA Y, et al. Fabrication of selfassembled monolayers (SAMs) and inorganic micropattern on flexible polymer substrate. Langmuir, 2004, 20(8): 3278-3283.

[37] ZEIRA A, CHOWDHURY D, HOEPPENER S, et al. Patterned organosilane monolayers as lyophobic lyophilic guiding templates in surface self-assembly: monolayer self-assembly versus wettingdriven self-assembly. Langmuir, 2009, 25(24): 13984-14001.

[38] BROCHARD F, PIERANSKI P, GUYON E. Dynamics of the orientation of a nematic-liquid-crystal film in a variable magnetic field. Physical Review Letters, 1972, 28(26): 1681-1683.

[39] BINKS B P. Particles as surfactants - similarities and differences. Current Opinion in Colloid \& Interface Science, 2002, 7(1/2): $21-41$.

[40] YANG P H, SUN W, HU S, et al. Self-assembly of nanoparticles at interfaces. Progress in Chemistry, 2014, 26(7): 1107-1119.

[41] TIWARI K, SARKAR P, MODAK S, et al. Large area selfassembled ultrathin polyimine nanofilms formed at the liquidliquid interface used for molecular separation. Adv. Mater, 2020, 32(8): 1905621. 
[42] LI Y J, HUANG W J, SUN S G. A universal approach for the self-assembly of hydrophilic nanoparticles into ordered monolayer films at a toluene/water interface. Angew. Chem. Int. Ed., 2006, 118(16): 2599-2601.

[43] LIANG X, XIANG J, ZHANG F, et al. Fabrication of hierarchical $\mathrm{CaCO}_{3}$ mesoporous spheres: particle-mediated self-organization induced by biphase interfaces and sams. Langmuir, 2010, 26(8): $5882-5888$.

[44] DOU Z, CAO C, WANG Q, et al. Synthesis, self-assembly, and high performance in gas sensing of X-shaped iron oxide crystals. ACS Appl. Mater. Interfaces, 2012, 4(10): 5698-5703.

[45] DOU H, LI M, QIAO Y, et al. Higher-order assembly of crystalline cylindrical micelles into membrane-extendable colloidosomes. Nat. Commun., 2017, 8(1): 426.

[46] AHN S, JUNG S Y, LEE S J. Self-assembly change by gold nanoparticle growth. J. Phys. Chem. C, 2011, 115(45): 22301-22308.

[47] LILJESTRÖM V, CHEN C, DOMMERSNES P, et al. Active structuring of colloids through field-driven self-assembly. Current Opinion in Colloid \& Interface Science, 2019, 40: 25-41.

[48] YAN K, XIONG Y, WU S, et al. Electro-molecular assembly: electrical writing of information into an erasable polysaccharide medium. ACS Appl. Mater. Interfaces, 2016, 8(30): 19780-19786.

[49] NIE Z, PETUKHOVA A, KUMACHEVA E. Properties and emerging applications of self-assembled structures made from inorganic nanoparticles. Nat. Nanotechnol., 2009, 5(1): 15-25.

[50] XING L, XIANG J, ZHANG F, et al. Free-standing array of multi-walled carbon nanotubes on silicon (111) by a field-inducing self-assembly process. Journal of Nanoscience and Nanotechnology, 2010, 10: 6376-6382.

[51] XING L, LI F, XIANG J, et al. Single walled carbon nanotubes (SWCNTs) assembled site-selectively on flexible substrate. Key Engineering Materials, 2010, 434: 761-763.

[52] MA Y, ZHAO W, SHE P, et al. Electric field induced molecular assemblies showing different nanostructures and distinct emission colors. Small Methods, 2019, 3: 1900718.

[53] CHANG H. Fields external to open-structure magnetic devices represented by ellipsoid or spheroid. British Journal of Applied Physics, 1961, 12(4): 160-163.

[54] WANG L, DONG S, HAO J. Recent progress of magnetic surfactants: self-assembly, properties and functions. Current Opinion in Colloid \& Interface Science, 2018, 35: 81-90.

[55] ABRAMSON S, DUPUIS V, NEVEU S, et al. Preparation of highly anisotropic cobalt ferrite/silica microellipsoids using an external magnetic field. Langmuir, 2014, 30(30): 9190-9200.

[56] SINGH G, CHAN H, BASKIN A, et al. Self-assembly of magnetite nanocubes into helical superstructures. Science, 2014, 345(6201): 1149-1153.

[57] LUO Z, EVANS B A, CHANG C. Magnetically actuated dynamic iridescence inspired by the neon tetra. ACS Nano, 2019, 13(4):
4657-4666.

[58] JI S, XU L, FU X, et al. Light- and metal ion-induced selfassembly and reassembly based on block copolymers containing a photoresponsive polypeptide segment. Macromolecules, 2019, 52(12): 4686-4693.

[59] HE J, CAO J, CHEN Y, et al. Thermoresponsive block copolymer vesicles by visible light-initiated seeded polymerization-induced self-assembly for temperature-regulated enzymatic nanoreactors. ACS Macro Lett., 2020, 9(4): 533-539.

[60] CHEN L, XU M, HU J, et al. Light-initiated in situ self-assembly (Lisa) from multiple homopolymers. Macromolecules, 2017, 9(4): 3540-3557.

[61] CHEN J, YUE X, XIAO Z, et al. In-situ synthesis of hydrophobic polyurethane ternary composite induced by hydroxyethyl cellulose through a green method for efficient oil removal. Polymers, 2020, 12: 509-520.

[62] CHEN J, XIANG J, YUE X, et al. Synthesis of a superhydrophobic polyvinyl alcohol sponge using water as the only solvent for continuous oil-water separation. Journal of Chemistry, 2019, 2019: 7153109.

[63] OZBAY E. Plasmonics: merging photonics and electronics at nanoscale dimensions. Science, 2006, 311: 189-193.

[64] BRYANT M A, CROOKS R M. Determination of surface $\mathrm{pKa}$ values of surface-confined molecules derivatized with $\mathrm{pH}$-sensitive pendant groups. Langmuir, 1993, 9(2): 385-387.

[65] TOKUHISA H, ZHAO M Q, BAKER L A, et al. Preparation and characterization of dendrimer monolayers and dendrimer alkanethiol mixed monolayers adsorbed to gold. J. Am. Chem. Soc., 1998, 120: 4492-4501.

[66] LEE J, GOVOROV A O, KOTOV N A, et al. Nanoparticle assemblies with molecular springs: a nanoscale thermometer. Angew. Chem. Int. Ed., 2005, 44: 7439-7442.

[67] ELGHANIAN R, STORHOFF J J, MUCIC R C, et al. Selective colorimetric detection of polynucleotides based on the distancedependent optical properties of gold nanoparticles. Science, 1997, 277(5329): 1078-1081.

[68] LEE J, HERNANDEZ P, LEE J, et al. Exciton-plasmon interactions in molecular spring assemblies of nanowires and wavelengthbased protein detection. Nat. Mater., 2007, 6(4): 291-295.

[69] CHOI Y, HO N H, TUNG C H. Sensing phosphatase activity by using gold nanoparticles. Angew. Chem. Int. Ed., 2007, 46: 707-709.

[70] LI H, ROTHBERG L. Colorimetric detection of DNA sequences based on electrostatic interactions with unmodified gold nanoparticles. Proceedings of the National Academy of Sciences of the United States of America, 2004, 101: 14036-14039.

[71] SÖNNICHSEN C, REINHARD B, LIPHARDT J, et al. A molecular ruler based on plasmon coupling of single gold and silver nanoparticles. Nat. Biotechnol., 2005, 23: 741-745. 
[72] REINHARD B, SHEIKHOLESLAMI S, MASTROIANNI A, et al. Use of plasmon coupling to reveal the dynamics of DNA bending and cleavage by single ecorv restriction enzymes. Proceedings of the National Academy of Sciences of the United States of America, 2007, 104: 2667-2672.

[73] LIU G, YIN Y, KUNCHAKARRA S, et al. A nanoplasmonic molecular ruler for measuring nuclease activity and DNA footprinting. Nat. Nanotechnol., 2006, 1: 47-52.

[74] ZHANG D, ZONG X, WU Z, et al. Hierarchical self-assembled $\mathrm{SnS}_{2}$ nanoflower $/ \mathrm{Zn}_{2} \mathrm{SnO}_{4}$ hollow sphere nanohybrid for humidity sensing applications. ACS Appl. Mater. Interfaces, 2018, 10: 32631-32639.

[75] YANG H M, MA S, YANG G J, et al. Synthesis of $\mathrm{La}_{2} \mathrm{O}_{3}$ doped $\mathrm{Zn}_{2} \mathrm{SnO}_{4}$ hollow fibers by electrospinning method and application in detecting of acetone. Applied Surface Science, 2017, 425: $585-593$.

[76] CHEN Z, CAO M, HU C. Novel $\mathrm{Zn}_{2} \mathrm{SnO}_{4}$ hierarchical nanostructures and their gas sensing properties toward ethanol. The Journal of Physical Chemistry C, 2011, 115: 5522-5529.

[77] WANG W, CHAI H, WANG X, et al. Ethanol gas sensing performance of $\mathrm{Zn}_{2} \mathrm{SnO}_{4}$ nanopowder prepared via a hydrothermal route with different solution pH values. Appl. Surf. Sci., 2015, 341: $43-47$.

[78] CHANG X, ZHOU Z, CONGDI S, et al. Coordination-driven self-assembled metallacycles incorporating pyrene: fluorescence mutability, tunability, and aromatic amine sensing. J. Am. Chem. Soc., 2019, 141: 1757-1765.

[79] HE Y, WANG R, JIAO T, et al. Facile preparation of selfassembled layered double hydroxide-based composite dye films as new chemical gas sensors. ACS Sustain. Chem. Eng., 2019, 7(12): 10888-10899.

[80] ROSSI N, GROSS B, DIRNBERGER F, et al. Magnetic force sensing using a self-assembled nanowire. Nano Letters, 2019, 19: 930-936.

[81] LI M, BHILADVALA R B, MORROW T J, et al. Bottom-up assembly of large-area nanowire resonator arrays. Nat. Nanotechnol., 2008, 3(2): 88-92.

[82] LISUNOVA Y, HEIDLER J, LEVKIVSKYI I, et al. Optimal ferromagnetically-coated carbon nanotube tips for ultra-high resolution magnetic force microscopy. Nanotechnology, 2013, 24(10): 105705 .

[83] LI X, YANG T, YANG Y, et al. Large-area ultrathin graphene films by single-step marangoni self-assembly for highly sensitive strain sensing application. Adv. Funct. Mater, 2016, 26: 1322-1329.

[84] YANG Y, XIAOYU W, QIANLING C, et al. Self-assembly of fluorescent organic nanoparticles for iron (iii) sensing and cellular imaging. ACS Appl. Mater. Interfaces, 2016, 8(11): 7440-7448.

[85] RUIBO Z, TANG Q, WANG S, et al. Self-assembly of enzyme-like nanofibrous g-molecular hydrogel for printed flexible electrochemical sensors. Adv. Mater., 2018, 30: 1706887.
[86] TAO Y, CHU F, GU X, et al. A novel electrochemical chiral sensor for tyrosine isomers based on a coordination-driven self-assembly. Sensors and Actuators B: Chemical, 2017, 255: 255-261.

[87] KNEIPP J, KNEIPP H, KNEIPP K. SERS-a single-molecule and nanoscale tool for bioanalytics. Chem. Soc. Rev., 2008, 37: 1052-1060.

[88] LIU K, ZHAO N, KUMACHEVA E. Self-assembly of inorganic nanorods. Chem. Soc. Rev., 2011, 40(2): 656-671.

[89] MA Y, HUANG Z, LI S, et al. Surface-enhanced Raman spectroscopy on self-assembled $\mathrm{Au}$ nanoparticles arrays for pesticides residues multiplex detection under complex environment. Nanomaterials, 2019, 9(3): 426.

[90] MAO M, ZHOU B, TANG X, et al. Natural deposition strategy for interfacial, self-assembled, large-scale, densely packed, monolayer film with ligand exchanged gold nanorods for in situ surface enhanced Raman scattering drug detection. Chemistry-A European Journal, 2018, 24(16): 4094-4102.

[91] ZHANG Y, TENG Y, REN Z, et al. Water/oil interfacial self-assembled gold nanoarrays modified on transparent tape for in situ surface-enhanced Raman scattering. Plasmonics, 2019, 14(5): 1105-1111.

[92] TIAN Y, ZHANG H, XU L, et al. Self-assembled monolayers of bimetallic $\mathrm{Au} / \mathrm{Ag}$ nanospheres with superior surface-enhanced Raman scattering activity for ultra-sensitive triphenylmethane dyes detection. Optics Letters, 2018, 43(4): 635-638.

[93] WANG L, QI H, CHEN L, et al. Self-assembled $\mathrm{Ag}-\mathrm{Cu}_{2} \mathrm{O}$ nanocomposite films at air-liquid interfaces for surface-enhanced Raman scattering and electrochemical detection of $\mathrm{H}_{2} \mathrm{O}_{2}$. Nanomaterials, 2018, 8(5): 332-342.

[94] MILLIKEN S, FRASER J, POIRIER S, et al. Self-assembled vertically aligned Au nanorod arrays for surface-enhanced Raman scattering (SERS) detection of Cannabinol. Spectrochimica Acta Part A: Molecular and Biomolecular Spectroscopy, 2018, 196: 222-228.

[95] TIAN X D, LIN Y, DONG J C, et al. Synthesis of Ag nanorods with highly tunable plasmonics toward optimal surface-enhanced Raman scattering substrates self-assembled at interfaces. Advanced Optical Materials, 2017, 5(21): 1700581.

[96] FREEMAN R, GRABAR K, ALLISON K, et al. Self-assembled metal colloid monolayers: an approach to SERS substrates. Science, 1995, 267: 1629-1632.

[97] CAMPION A, KAMBHAMPATI P. Surface-enhanced Raman scattering. Chem. Soc. Rev., 1998, 27(4): 241-250.

[98] ZHANG B, WANG H S, LU L, et al. Large-area silver coated silicon nanowire arrays for molecular sensing using surface enhanced Raman spectroscopy. Adv. Funct. Mater., 2008, 18: 2348-2355.

[99] POTARA M, MANIU D, ASTILEAN S. The synthesis of biocompatible and SERS-active gold nanoparticles using chitosan. Nanotechnology, 2009, 20(31): 315602. 
[100] CONG S, YUAN Y, CHEN Z, et al. Noble metal-comparable SERS enhancement from semiconducting metal oxides by making oxygen vacancies. Nat. Commun., 2015, 6: 7800.

[101] LAN C, ZHAO J, ZHANG L, et al. Self-assembled nanoporous graphene quantum dot- $\mathrm{Mn}_{3} \mathrm{O}_{4}$ nanocomposites for surfaceenhanced Raman scattering based identification of cancer cells. RSC Adv., 2017, 7: 18658-18667.

[102] YI K, WANG H, LU Y, et al. Enhanced Raman scattering by self-assembled silica spherical microparticles. Journal of Applied Physics, 2007, 101(6): 063528.

[103] NG V M H, HUANG H, ZHOU K, et al. Recent progress in layered transition metal carbides and/or nitrides (MXenes) and their composites: synthesis and applications. J. Mater. Chem. A, 2016, 5(7): 3039-3068.

[104] CHEN K, YAN X, LI J, et al. Preparation of self-assembled composite films constructed by chemically-modified MXene and dyes with surface-enhanced Raman scattering characterization. Nanomaterials, 2019, 9(2): 284.

[105] LIU P, PAN X, YANG W, et al. Improved anticorrosion of magnesium alloy via layer-by-layer self-assembly technique combined with micro-arc oxidation. Materials Letters, 2012, 75: 118-121.

[106] ZHOU Y, HUANG W, LIU J, et al. Self-assembly of hyperbranched polymers and its biomedical applications. Adv. Mater., 2010, 22(41): 4567-4590.

[107] KIM B S, CHOI J W. Polyelectrolyte multilayer microcapsules: self-assembly and toward biomedical applications. Biotechnology and Bioprocess Engineering, 2007, 12(4): 323-332.

[108] ZHOU J, PISHKO M, LUTKENHAUS J. Thermo-responsive layer-by-layer assemblies for nanoparticle-based drug delivery. Langmuir, 2014, 30(20): 5903-5910.

[109] PATEL D, RANA D, ASWAL V, et al. Influence of graphene on self-assembly of polyurethane and evaluation of its biomedical properties. Polymer, 2015, 65: 183-192.

[110] ZHAO H, HE W, WANG Y, et al. Biomineralization of large hydroxyapatite particles using ovalbumin as biosurfactant. Materials Letters, 2008, 62(20): 3603-3605.

[111] SAMANO E, PILO-PAIS M, GOLDBERG S, et al. Selfassembling DNA templates for programmed artificial biomineralization. Soft Matter, 2011, 7(7): 3240-3245.

[112] GRÖGER C, LUTZ K, BRUNNER E. Biomolecular self-assembly and its relevance in silica biomineralization. Cell Biochemistry and Biophysics, 2008, 50(1): 23-39.

[113] GUNGORMUS M, BRANCO M, FONG H, et al. Self assembled bi-functional peptide hydrogels with biomineralization-directing peptides. Biomaterials, 2010, 31(28): 7266-7274.

[114] ZERFASS C, BRAUKMANN S, NIETZSCHE S, et al. High yield recombinant production of a self-assembling polycationic peptide for silica biomineralization. Protein Expression and Purification, 2015, 108: 1-8.

[115] NEGAH S, KHAKSAR Z, ALIGHOLI H, et al. Enhancement of neural stem cell survival, proliferation, migration, and differen- tiation in a novel self-assembly peptide nanofibber scaffold. Molecular Neurobiology, 2017, 54(10): 8050-8062.

[116] OUBERAI M M, GOMES DOS SANTOS A L, MADALLI S, et al. Controlling the bioactivity of a peptide hormone in vivo by reversible self-assembly. Nat. Commun., 2017, 8(1): 1026.

[117] CHEN C, HU J, ZHANG S, et al. Molecular mechanisms of antibacterial and antitumor actions of designed surfactant-like peptides. Biomaterials, 2012, 33: 592-603.

[118] CHEN C, PAN F, ZHANG S, et al. Antibacterial activities of short designer peptides: a link between propensity for nanostructuring and capacity for membrane destabilization. Biomacromolecules, 2010, 11: 402-411.

[119] BAI J, CHEN C, WANG J, et al. Enzymatic regulation of selfassembling peptide $\mathrm{A}_{9} \mathrm{~K}_{2}$ nanostructures and hydrogelation with highly selective antibacterial activities. ACS Appl. Mater. Interfaces, 2016, 8(24): 15093-15102.

[120] CHEN C, ZHANG Y, FEI R, et al. Hydrogelation of the short self-assembling peptide $\mathrm{I}_{3} \mathrm{QGK}$ regulated by transglutaminase and use for rapid hemostasis. ACS Appl. Mater. Interfaces, 2016, 8(28): 17833-17841

[121] HU Z, PANTOŞ G D, KUGANATHAN N, et al. Interactions between amino acid-tagged naphthalenediimide and single walled carbon nanotubes for the design and construction of new bioimaging probes. Adv. Funct. Mater., 2012. 22(3): 503-518.

[122] HU Z, ARROWSMITH R L, TYSON J A, et al. A fluorescent Arg-Gly-Asp (Rgd) peptide-naphthalenediimide (NDI) conjugate for imaging integrin $\alpha_{\mathrm{v}} \beta_{3}$ in vitro. Chem. Comm., 2015, 51(32): 6901-6904

[123] MCCLURE S A, WORFOLK B J, RIDER D A, et al. Electrostatic layer-by-layer assembly of CdSe nanorod/polymer nanocomposite thin films. ACS Appl. Mater. Interfaces, 2010, 2(1): 219-229.

[124] GUPTA S, ZHANG Q, EMRICK T, et al. "Self-corralling" nanorods under an applied electric field. Nano Letters, 2006, 6(9): 2066-2069.

[125] RIVEST J B, SWISHER S L, FONG L K, et al. Assembled monolayer nanorod heterojunctions. ACS Nano, 2011, 5(5): 3811-3816.

[126] WANG W, CHAU Y. Self-assembled peptide nanorods as building blocks of fractal patterns. Soft Matter, 2009, 5(24): 4893-4898.

[127] LI Z, XING L, XIANG J, et al. Morphology controlling of calcium carbonate by self-assembled surfactant micelles on pet substrate. RSC Advances, 2014, 4(59): 31210.

[128] RECHES M, GAZIT E. Casting metal nanowires within discrete self-assembled peptide nanotubes. Science, 2003, 300(5619): $625-627$.

[129] RECHE S, MEITA L, GAZI T, et al. Casting metal nanowires within discrete self-assembled peptide nanotubes. Science, 2003, 299: $1877-1881$.

[130] MURRAY R W. Nanoelectrochemistry: metal nanoparticles, nanoelectrodes, and nanopores. Chem. Rev., 2008, 108(7): 2688-2720. 